\title{
The CANLEX project: summary and conclusions
}

\author{
P.K. Robertson, C.E. (Fear) Wride, B.R. List, U. Atukorala, K.W. Biggar, \\ P.M. Byrne, R.G. Campanella, D.C. Cathro, D.H. Chan, K. Czajewski, W.D.L. Finn, \\ W.H. Gu, Y. Hammamji, B.A. Hofmann, J.A. Howie, J. Hughes, A.S. Imrie, \\ J.-M. Konrad, A. Küpper, T. Law, E.R.F. Lord, P.A. Monahan, N.R. Morgenstern, \\ R. Phillips, R. Piché, H.D. Plewes, D. Scott, D.C. Sego, J. Sobkowicz, \\ R.A. Stewart, B.D. Watts, D.J. Woeller, T.L. Youd, and Z. Zavodni
}

\begin{abstract}
The Canadian geotechnical engineering community has completed a major collaborative 5 year research project entitled the Canadian Liquefaction Experiment (CANLEX). The main objective of the project was to study the phenomenon of soil liquefaction, which can occur in saturated sandy soils and is characterized by a large loss of strength or stiffness resulting in substantial deformations. The intent of this paper is to compare, interpret, and summarize the large amount of field and laboratory data obtained for six sites in Western Canada as part of the CANLEX project. The sites are compared in terms of both flow-liquefaction and cyclic-softening considerations. The paper presents a number of conclusions drawn from the project as a whole, in terms of both fundamental and practical significance.
\end{abstract}

Key words: sand, flow liquefaction, cyclic softening, CANLEX.

\begin{abstract}
Résumé : La communauté canadienne d'ingénieurs géotechniciens a réalisé en collaboration un projet majeur de recherche sur une période de 5 ans intitulé Canadian Liquefaction Experiment (CANLEX). L'objectif principal du projet a été d'étudier le phénomène de la liquéfaction des sols qui peut se produire dans les sols sableux saturés et qui est caractérisée par une perte importante de la résistance ou de la rigidité résultant en de grandes déformations. Le but de cet article est de comparer, d'interpréter et de résumer la grande quantité de données de terrain et de laboratoire obtenues pour les six sites de l'Ouest canadien dans le cadre du projet CANLEX. Les sites sont comparés en fonction de considérations tant sur l'écoulement par liquéfaction que sur le ramollissement cyclique. Cet article présente un certain nombre de conclusions tirées du projet dans son ensemble, en fonction de leurs significations tant théoriques que pratiques.
\end{abstract}

Mots clés : sable, écoulement par liquéfaction, ramollissement cyclique, CANLEX.

[Traduit par la Rédaction]

\section{Introduction}

The Canadian Liquefaction Experiment (CANLEX) project has involved the investigation of six sites in Western Canada containing loose sand deposits. The phase I and phase III sites were located at the Syncrude Canada Lid. oil sands mine north of Fort McMurray, Alberta, the two phase II sites in the Fraser River delta just south of Vancouver, British Columbia, and the two phase IV sites at the Highland Valley Copper (HVC) mine south of Kamloops, British Columbia. The investigations involved ground freezing and sampling as well as conventional sampling to obtain soil samples from each site. Extensive in situ testing was

Received December 10, 1998. Accepted May 1, 2000.

P.K. Robertson'. Geotechnical Group, Department of Civil and Environmental Engineering, University of Alberta, Edmonton, AB T6G 2G7, Canada.

'Corresponding author.

${ }^{2}$ All results from the CANLEX project are contained in summary data reports available from BiTech Publishers Ltd., 173 - 1180 Hammersmith Way, Richmond, BC V7A 5G1, Canada. also performed at each site, including standard penetration tests (SPT), cone penetration tests (CPT), seismic CPT (giving shear wave velocity measurements), self-boring pressuremeter testing (SBPMT), and geophysical (gamma-gamma) logging. Laboratory testing was carried out on both reconstituted samples and the undisturbed samples obtained by ground freezing and sampling. The testing consisted of triaxial compression, triaxial extension, and simple shear tests (generally under undrained conditions, although some drained tests were performed); both monotonic and cyclic tests were performed.

The intent of this paper is to compare, interpret, summarize, and draw conclusions from the large amount of field and laboratory data obtained for six sites in Western Canada as part of the CANLEX project. The sites are compared in terms of both flow-liquefaction and cyclic-softening considerations. Details of methods and results on almost all aspects of the CANLEX project have been presented in numerous internal CANLEX reports. The specific methods used in the data review process are outlined by Wride and Robertson (1997a). Results from each phase of the project have been presented in data review reports (Wride and Robertson $1997 b, 1997 c, 1997 d) .^{2}$ The results are also described in four companion papers (Byrne et al. 2000; Robertson et al. 2000; Wride et al. 2000a, 2000b). 
Tahle 1. Summary of the target zone data for each CANLEX site.

\begin{tabular}{|c|c|c|c|c|c|c|c|c|c|}
\hline \multicolumn{6}{|c|}{ Site data } & \multicolumn{4}{|c|}{ Average in situ stresses } \\
\hline Phase & Location & Site & $\begin{array}{l}\text { Approximate } \\
\text { age at time } \\
\text { of testing }\end{array}$ & $\begin{array}{l}\text { Target } \\
\text { zone }(\mathrm{m})\end{array}$ & $\begin{array}{l}\text { Average } \\
\text { depth of } \\
\text { GWT (m)* }\end{array}$ & $\begin{array}{l}\sigma_{\mathrm{v}}^{\prime} \\
(\mathrm{kPa})\end{array}$ & $\begin{array}{l}\sigma_{h}^{\prime} \\
(\mathrm{kPa})\end{array}$ & $\begin{array}{l}p^{\prime} \\
(\mathrm{kPa})\end{array}$ & $\begin{array}{l}q \\
(\mathrm{kPa})\end{array}$ \\
\hline I & Syncrude & Mildred Lake & 12 years & $27-37$ & 21 & 495 & 248 & 330 & 248 \\
\hline \multirow[t]{2}{*}{ II } & Fraser River delta & Massey & 200 years & $8-13$ & 1.5 & 115 & 58 & 77 & 58 \\
\hline & & Kidd & 4000 years & $12-17$ & 1.5 & 154 & 77 & 103 & 77 \\
\hline III & Syncrude & $J_{\text {-pit }}$ & 2 months & $3-7$ & 0.5 & 53 & 26 & 35 & 26 \\
\hline \multirow[t]{2}{*}{ IV } & HVC Mine & LL Dam & 5 years & $6-10$ & 2.1 & 96 & 48 & 64 & 48 \\
\hline & & Highmont Dam & 15 years & $8-12$ & 4 & 132 & 66 & 88 & 66 \\
\hline
\end{tabular}

Note: Average in situ stresses are based on a unit weight of $\gamma=18.5 \mathrm{kN} / \mathrm{m}^{3}$ above the groundwater table (GWT), $\gamma=19.5 \mathrm{kN} / \mathrm{m}^{3}$ below GWT, and $K_{0}=0.5 ; p^{\prime}=1 / 3\left(\sigma_{v}^{\prime}+2 K_{0} \sigma_{v}^{\prime}\right) ; q=\sigma_{v}^{\prime} K_{0} \sigma_{v}^{\prime}$

*Tidal fluctuations occur at the Massey and Kidd sites.

\section{Liquefaction definitions}

It is important to first define the terms used to explain the phenomena of soil liquefaction. The definitions adopted by the CANLEX project are illustrated in Fig. 1. The flow chart presented in Fig. 1 specifically distinguishes between flow liquefaction (i.e., strain-softening behaviour during undrained loading) and cyclic softening. Cyclic softening is further divided into cyclic liquefaction and cyclic mobility. Historically, the most common form of soil liquefaction observed in the field has been cyclic liquefaction due to earthquake loading. Thus, much of the existing research on soil liquefaction has been related to cyclic softening, primarily cyclic liquefaction. Cyclic liquefaction generally applies to level or gently sloping ground in which shear stress reversal occurs during cyclic (e.g., earthquake) loading.

The three main concerns related to soil liquefaction are generally as follows:

- Will an event (e.g., a design earthquake) trigger significant zones of liquefaction?

- If a soil is potentially strain softening (and is triggered to liquefy), what will be the resulting residual (minimum) undrained shear strength?

- If liquefaction is triggered, what displacements will result?

The CANLEX project attempted to address these concerns through collaborative research studying sands from six sites in Western Canada. Both cyclic and flow liquefaction were studied; however, emphasis was placed on flow liquefaction, since less work has been carried out on this topic in the past.

\section{Test sites}

Table 1 summarizes the general site data for each of the six CANLEX sites, including the location and approximate age of each deposit, location of the target zone, depth to the groundwater table, and average target zone in situ stresses at each site. It is interesting to note that the age of the deposits varied from as young as 2 months to as old as 4000 years. Note also that the vertical effective stress in the target zones varied from as low as $53 \mathrm{kPa}$ to as high as $495 \mathrm{kPa}$, with an overall average of $174 \mathrm{kPa}$. Based on the results of this study, the sands at the CANLEX sites are of Holocene age (i.e., less than 10000 years old), are essentially normally consolidated and appear to be uncemented, and are com-
Fig. 1. Suggested flow chart for evaluation of soil liquefaction (after Robertson 1994).

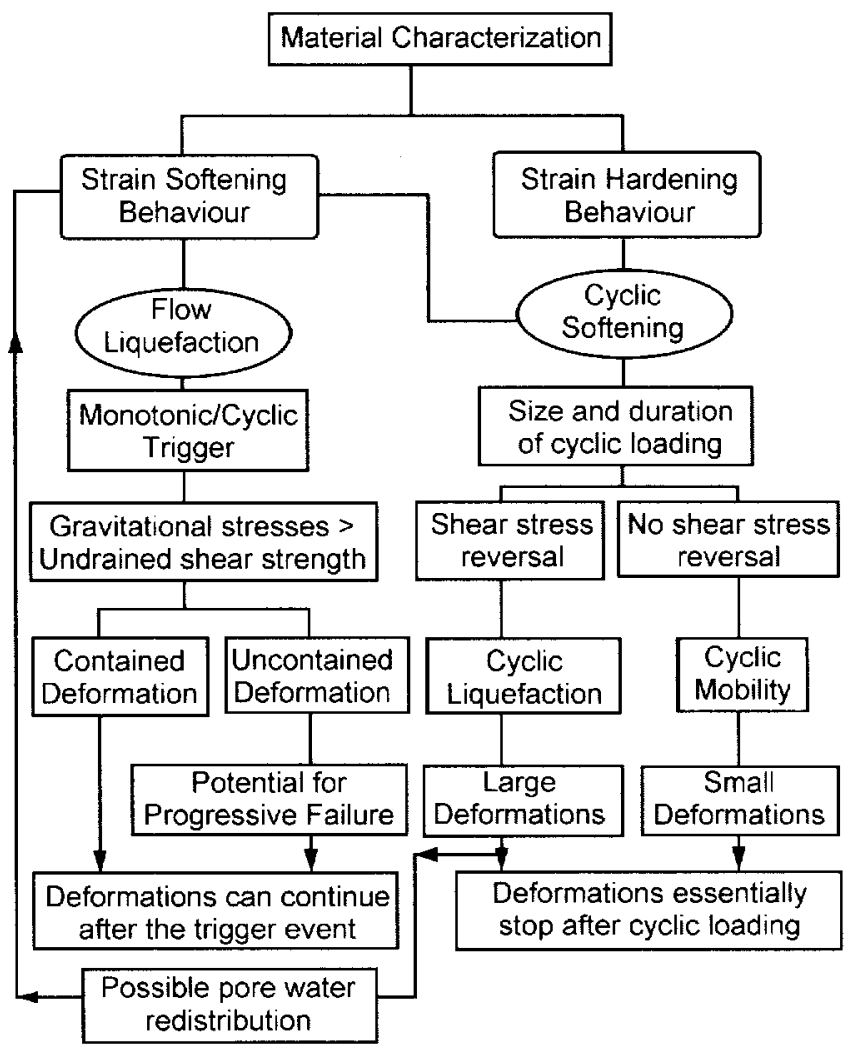

posed primarily of quartz minerals with small amounts of feldspar and mica. The Fraser River sand has higher contents of mica and feldspar. These sands are uniformly graded with a mean grain size $\left(D_{50}\right)$ of $0.16-0.25 \mathrm{~mm}$ and a fines content, in general, less than $15 \%$, with some less than $5 \%$.

Undisturbed samples of sand were obtained from the target zone at the centre of each of the six sites using ground freezing and sampling techniques. In addition, typically along a $5 \mathrm{~m}$ radius around the central ground freezing location, in situ testing through the target zone at each site consisted of the following: CPT, SPT, shear wave velocity $\left(V_{\mathrm{s}}\right)$ measurements (seismic CPT), geophysical logging, and pressuremeter testing. 
Table 2. Index properties for the six CANLEX sites.

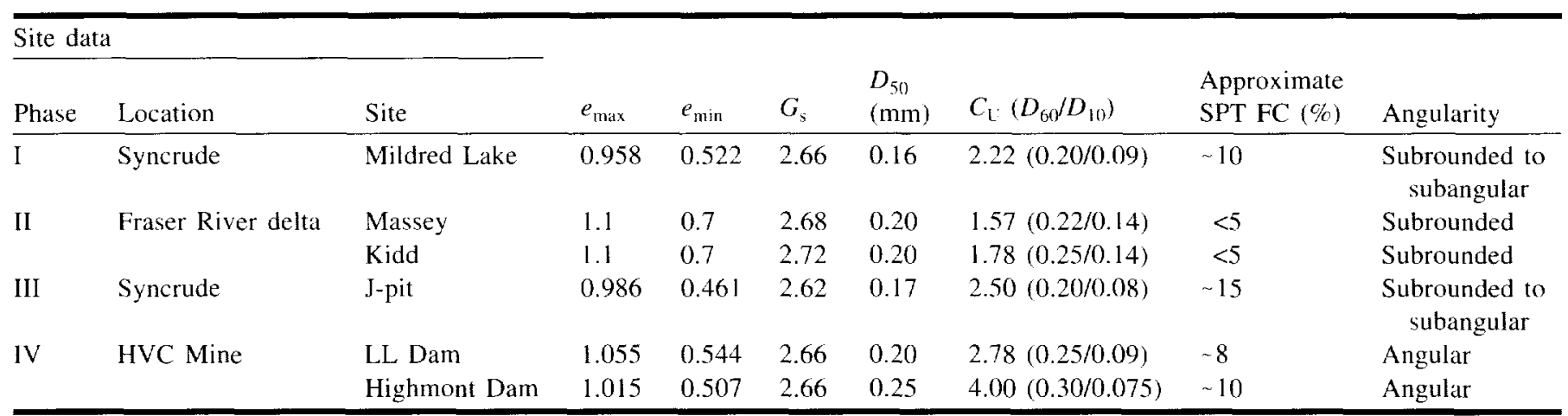

Note: Maximum and minimum void ratios $\left(e_{\max }\right.$ and $e_{\min }$, respectively) and specific gravity $\left(G_{\mathrm{s}}\right)$ determined using American Society for Testing and Materials (ASTM) standards. $D_{\mathrm{t}}$, size of particle $(\mathrm{mm})$ such that $x \%$ of the particles are smaller; $C_{\mathrm{t}}$. coefficient of uniformity $=D_{t 0 \mathrm{~b}} D_{00}$ : FC, approximate average fines content (percent passing No. 200 sieve) in the target zone, based on limited SPT samples.

Table 3. Summary SPT, CPT, and shear wave velocity results from the six CANLEX sites.

\begin{tabular}{|c|c|c|c|c|c|c|}
\hline \multicolumn{3}{|c|}{ Site data } & \multicolumn{4}{|l|}{ Field data } \\
\hline Phase & Location & Site & SPT $\left(N_{1}\right)_{60}$ & $\mathrm{CPT} q_{\mathrm{c}}(\mathrm{MPa})$ & $\mathrm{CPT} F(\%)$ & Shear wave velocity $V_{\mathrm{sl}}(\mathrm{m} / \mathrm{s})$ \\
\hline I & Syncrude & Mildred Lake & $18.2(3.0)$ & $7.38(1.67)$ & $0.727(0.150)$ & $156.4(20.1)$ \\
\hline & & Kidd & $13.4(2.9)$ & $6.83(1.77)$ & $0.369(0.048)$ & $177.4(5.4)$ \\
\hline III & Syncrude & $J$-pit & $3.4(2.0)$ & $2.04(0.79)$ & $0.872(0.331)$ & $127.1(3.0)$ \\
\hline IV & HVC Mine & LL Dam & $5.4(1.6)$ & $3.94(0.78)$ & $0.409(0.096)$ & $153.1(15.3)$ \\
\hline
\end{tabular}

Note: Numbers in the table are overall average values in the target zone, with standard deviations in parentheses. $\left(N_{1}\right)_{60}$, SPT $N$ value corrected for overburden stress and corrected to an energy ratio of $60 \%$ (see Wride et al. $2000 \mathrm{~b}$ ); $q_{\mathrm{cl}}$. CPT penetration resistance corrected for overburden stress (see Wride et al. $2000 b) ; F$. CPT friction ratio $=f\left(q_{c}-\sigma_{v}\right) \times 100 \%$, where $f_{\mathrm{s}}$ is the sleeve friction: $V_{\mathrm{s}}$, measured shear wave velocity corrected for overburden stress (see Wride et al. 2000b).

An additional site that can be incorporated into this study is Duncan Dam, which is a zoned earthfill hydroelectric dam located on the Duncan River, about $8 \mathrm{~km}$ upstream from Kootenay Lake in southeastern British Columbia. Prior to the start of the CANLEX project, a similar type of detailed field and laboratory investigation was carried out at Duncan Dam to characterize the sandy soil beneath the dam as part of a dam safety review by B.C. Hydro (Little et al. 1994).

\section{Summary of test results}

\section{Field results}

Table 2 summarizes and compares the index properties and grain characteristic parameters for each of the six CANLEX sites. Table 3 summarizes the overall target zone average (and standard deviation) values for each of the parameters that were measured as part of the in situ testing at the six CANLEX sites. Details on the fieldwork are contained in companion papers.

\section{Laboratory results}

Samples for laboratory testing were trimmed from the frozen core, which was obtained from the six CANLEX sites using ground freezing and sampling. Trimmed groundfreezing samples from the six sites were tested in undrained triaxial compression, triaxial extension, and simple shear as well as cyclic triaxial and cyclic simple shear. A few samples were tested in drained triaxial loading. At most of the sites, some frozen core was thawed and used to form reconstituted samples, which were tested in triaxial and (or) simple shear loading.

When loose samples of sand are loaded in undrained shear, they can strain soften, eventually reaching an ultimate condition referred to as critical or steady state. In the CANLEX project, this ultimate condition at large strains is referred to as ultimate state, as recommended by Poorooshasb and Consoli (1991). The ultimate state can be used as a reference to define the state of a sand (Been and Jefferies 1985).

There is much discussion in the literature on the possible uniqueness of the ultimate (steady or critical) state line. The objective of this research is not to comment on the validity of a given concept or theory, but to obtain data to evaluate the appropriateness of a published concept or approach for the assessment of liquefaction potential. To evaluate the appropriateness of state parameter requires the determination of an ultimate state line (USL) for a given sand.

Based on the laboratory testing, three bilinear reference USLs were determined for the six CANLEX sites as follows: Syncrude reference USL for phases I and III, Fraser River reference USL for Massey and Kidd, and Highland Valley Copper (HVC) reference USL for LL Dam and Highmont Dam. Since the state parameter approach was based on triaxial compression test data, the reference USLs were established based primarily on results from triaxial compression tests on loose reconstituted samples. Figure 2 
Fig. 2. Comparison of the CANLEX reference ultimate state lines (USLs) with those for other sands, as summarized by Sasitharan et al. (1994)

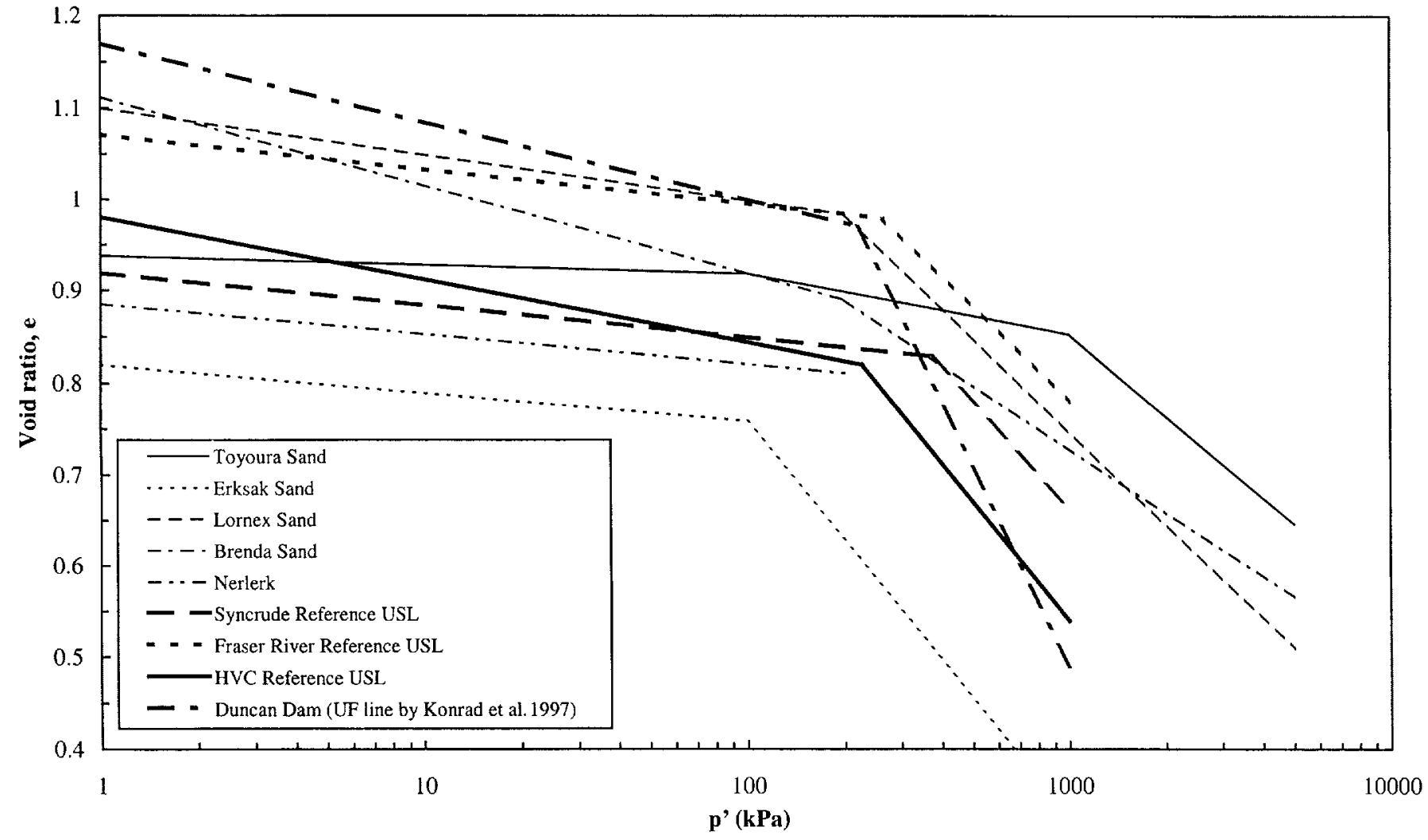

Table 4. Reference ultimate state lines (USLs) for CANLEX sites and Duncan Dam.

\begin{tabular}{|c|c|c|c|c|}
\hline \multicolumn{3}{|c|}{ Site data } & \multicolumn{2}{|l|}{ Reference USL } \\
\hline Phase & Location & Site & $\Gamma^{*}$ & $\lambda_{\text {ln }} \div$ \\
\hline I. III & Syncrude & Mildred Lake Settling Basin, J-pit & $0.919(e>0.829)$ & $\begin{array}{l}0.0152(e>0.829) \\
1.92(e<0.829)\end{array}$ \\
\hline II & Fraser River delta & Massey, Kidd & $1.071(e>0.979)$ & $\begin{array}{l}0.0165(e>0.829) \\
1.80(e<0.979)\end{array}$ \\
\hline IV & HVC Mine & LL Dam, Highmont Dam & $0.98(e>0.82)$ & $\begin{array}{l}0.0295(e>0.82) \\
1.645(e<0.82)\end{array}$ \\
\hline Other & Duncan Dam, unit 3-c sand & Beneath dam toe, where ground freezing was done & $1.17(e>0.97)$ & $\begin{array}{l}0.0371 \quad(e>0.97) \\
2.678(e<0.97)\end{array}$ \\
\hline
\end{tabular}

$*$ Void ratio at $p^{\prime}=1 \mathrm{kPa}$.

Slope of the USL in $e-p^{\prime}$ space, when the $p^{\prime}$ axis is on a natural logarithm scale.

Parameters for USL line determined by Konrad et al. (1997).

presents a comparison between these USLs and the USLs for some other sandy soils (Sasitharan et al. 1994). Ishihara (1993) has shown that the USL is curved in void ratio - log effective stress space $\left(e-\log p^{\prime}\right)$. To simplify the application of a USL, the authors have selected to represent the curved USL as being bilinear. Although simplistic, a bilinear USL allows a clear link to previous published approaches based on state in the low stress range $\left(p^{\prime}<200 \mathrm{kPa}\right)$. Each portion of the bilinear USLs can be defined as follows:

[1] $e=\Gamma-\lambda_{\ln } \ln \left(p^{\prime}\right)$

where

$e$ is the void ratio; $p^{\prime}$ is the mean normal effective stress $=1 / 3\left(\sigma_{v_{0}}^{\prime}+\right.$ $2 K_{0} \sigma_{\mathrm{vo}}^{\prime}$ ), where $\sigma_{\mathrm{vo}}^{\prime}$ is the vertical consolidation pressure; $\Gamma$ is the void ratio at $p^{\prime}=1 \mathrm{kPa}$; and

$\lambda_{\ln }$ is the slope of the USL in $e-p^{\prime}$ space, when the $p^{\prime}$ axis is on a natural logarithm scale $\left(\lambda_{\text {log }}=2.302 \lambda_{\mathrm{In}}\right)$.

The values of $\Gamma$ and $\lambda_{\ln }$ for the three CANLEX reference USLs are given in Table 4 . In addition, Table 4 gives values of $\Gamma$ and $\lambda_{\text {In }}$ for unit 3-c sand at Duncan Dam, based on the USL proposed by Konrad et al. (1997).

\section{Analysis of results}

The following sections examine the results of applying various existing methods for estimating soil state, cyclic 
Table 5. Summary of ground-freezing sample states.

\begin{tabular}{|c|c|c|c|c|c|c|}
\hline \multicolumn{3}{|c|}{ Site data } & \multicolumn{4}{|c|}{ In situ state based on ground-freezing samples } \\
\hline Phase & Location & Site & $\begin{array}{l}\text { No. of trimmed } \\
\text { samples }\end{array}$ & Void ratio $(e)$ & $\begin{array}{l}\text { Relative density } \\
D_{\mathrm{r}}(\%)\end{array}$ & State parameter $\Psi^{*}$ \\
\hline \multirow[t]{2}{*}{ II } & Fraser River delta & Massey & $43(25 \mathrm{TX}, 18 \mathrm{SS})$ & $0.97(0.05)$ & $32.5(12.5)$ & $-0.029(0.048)$ \\
\hline & & Kidd & $18(10 \mathrm{TX}, 8 \mathrm{SS})$ & $0.981(0.076)$ & $29.8(19.0)$ & $-0.002(0.082)$ \\
\hline III & Syncrude & J-pit & $47(34 \mathrm{TX}, 13 \mathrm{SS})$ & $0.762(0.053)$ & $42.7(10.1)$ & $-0.106(0.053)$ \\
\hline
\end{tabular}

\footnotetext{
Note: Numbers in the table are overall average values in the target zone, with standard deviations in parentheses. SS, simple shear specimens; TX, biaxial specimens.

* Relative to the reference USL.
}

liquefaction potential, and flow liquefaction potential to the field and laboratory data from the six CANLEX sites.

\section{State}

A number of parameters can be used to define the state of a sandy soil, namely void ratio $(e)$, relative density $\left(D_{\mathrm{r}}\right)$, and state parameter $(\boldsymbol{\Psi})$. Table 5 summarizes these parameters for the undisturbed samples from the target zone at each CANLEX site which were obtained using ground freezing and sampling and then trimmed for testing. The application of various published methods for estimating these parameters at the six CANLEX sites is discussed later in the paper. The in situ test signatures $\left(\left(N_{1}\right)_{60}, q_{\mathrm{cl}}, V_{\mathrm{s} 1}\right)$ can also be regarded as direct measures of in situ state. Table 3 presents a summary of the normalized in situ test parameters.

\section{Void ratio and relative density}

Void ratios were calculated (using volume calculations) for each ground-freezing sample that was trimmed for testing (see Table 5). Based on the minimum $\left(e_{\min }\right)$ and maximum $\left(e_{\max }\right)$ void ratios given in Table 2 , values of relative density were also determined for each sample. In addition, the various in situ tests were interpreted to estimate void ratio and (or) relative density. A companion paper (Wride et al. $2000 \mathrm{~b}$ ) compares and discusses these results in detail and shows that aging appears to be an important factor in the various correlations between in situ test results (SPT, CPT, or $V_{s}$ ) and void ratio or relative density, with older sands having a higher penetration resistance or measured shear wave velocity for a given relative density. Table 5 shows that the in situ relative densities at the six CANLEX sites are highly variable, with overall average values ranging from 30 to $44 \%$ and standard deviations of $8-19 \%$. These six CANLEX sites were selected in an effort to study sites that contained relatively uniform loose sand deposits. A major observation from the project has been the extremely large variability in in situ relative density of these "uniform" sand deposits. This is consistent with past experience where sands have generally been described as heterogeneous in nature.

\section{State parameter $(\Psi)$}

Void ratio and initial mean normal effective stress, $p_{i}^{\prime}$, can be combined in terms of state parameter $(\Psi)$, as proposed by Been and Jefferies (1985), relative to a reference USL. $\Psi$ is the difference between the initial void ratio of the sample and the void ratio on the USL at the same value of $p^{\prime}$. Soils with $\Psi>0$ are loose of the reference USL, and those with $\Psi<0$ are dense of the reference USL. Since a reference USL was selected for each pair of CANLEX sites (Syncrude, Fraser River, and HVC), values of state parameter were calculated for each ground-freezing sample that was trimmed for testing (see Table 5). Table 5 shows that the overall average in situ state parameter at the six CANLEX sites ranges from -0.002 to -0.064 , with standard deviations of 0.04-0.08. In general, the average overall state of these deposits was slightly dense of the reference USL, with a small percentage loose of the reference USL.

CPT-based estimates of $\Psi$ : Profiles of state parameter were estimated by interpreting CPT results from each of the CANLEX test sites using the methods proposed by both Been and Jefferies (1992) and Plewes et al. (1992). A companion paper (Wride et al. 2000b) provides a detailed discussion of the CPT-based approaches to estimate $\Psi$ and identified the following:

(1) The method by Been and Jefferies (1992) gave rather poor predictions of $\Psi$. This may be due to some uncertainty in determining the USL, combined with the effect of age of the deposits, similar to that observed in estimating relative density.

(2) The method by Plewes et al. (1992) provided quite good predictions of $\Psi$. The range in $\Psi$ from the frozen samples was larger than that predicted based on the CPT. Again, age appears to have an influence on the interpretation, with older deposits (Kidd and Massey) both predicting slightly denser states. In general, the CPT-predicted in situ state was slightly dense of the reference USL at each site. The CPT also confirmed the large variability in in situ state at each site.

Some of the differences between the SPT- and CPT-based predictions of relative density and state parameter and the values of relative density and state parameter associated with the frozen samples may be due, in part, to the effect of physical scale on the measurement. The SPT and CPT are influenced by a volume of soil which is significantly larger than that of the individual frozen samples and, therefore, may produce more subdued variations in void ratio compared to the samples. Image analysis (Hanzawa 1980) has shown that void ratio measurements can vary significantly, depending on the size of the sample.

Pressuremeter-based estimates of $\Psi$ : Yu et al. (1996) proposed that the self-boring pressuremeter (SBPMT) can be 
Table 6. Summary of cyclic liquefaction for each CANLEX site based on laboratory testing.

\begin{tabular}{|c|c|c|c|c|c|c|}
\hline \multicolumn{3}{|c|}{ Site data } & \multicolumn{2}{|c|}{$\begin{array}{l}\text { All tested samples (for phase I and LL } \\
\text { Dam; includes some samples with } S_{\mathrm{r}}<100 \% \text { ) }\end{array}$} & \multicolumn{2}{|c|}{$\begin{array}{l}\text { For phase I and LL Dam } \\
\text { (samples with } S_{\mathrm{r}} \approx 100 \% \text { only) }\end{array}$} \\
\hline Phase & Location & Site & $\begin{array}{l}\text { No. and types of } \\
\text { tests* }\end{array}$ & $\begin{array}{l}\text { Equivalent } \mathrm{CRR}_{\mathrm{ss}} \\
M 7.5^{\dagger}\end{array}$ & $\begin{array}{l}\text { No. and types } \\
\text { of tests* }\end{array}$ & $\begin{array}{l}\mathrm{CRR}_{\mathrm{ss}}, M 7.5 \\
\left(\sigma_{\mathrm{v}}^{\prime}=1\right. \\
\mathrm{atm})^{\ddagger}\end{array}$ \\
\hline I & Syncrude & Mildred Lake Settling Basin & 4 CTX & $0.226(0.078)^{8}$ & 2 of 4 CTX & $0.22^{\ddagger 1}$ \\
\hline \multirow[t]{2}{*}{ II } & Fraser River delta & Massey & $13 \mathrm{CSS}$ & $0.101(0.018)$ & & \\
\hline & & Kidd & $6 \mathrm{CSS}$ & $0.098(0.017)$ & & \\
\hline III & Syncrude & J-pit & $5 \mathrm{CSS}$ & $0.082(0.006)$ & & \\
\hline \multirow[t]{2}{*}{ IV } & HVC Mine & LL Dam & 4 CTX & $0.144(0.043)^{8}$ & 2 of 4 CTX & $0.112^{\S}$ \\
\hline & & Highmont Dam & 4 CTX & $0.107(0.014)^{\S}$ & & \\
\hline Other & $\begin{array}{l}\text { Duncan Dam unit } \\
\text { 3-c sand }\end{array}$ & $\begin{array}{l}\text { Beneath dam toe, where } \\
\text { ground freezing was done }\end{array}$ & $\begin{array}{l}3 \text { CSS, with no } \\
\text { initial static } \\
\text { bias and } \sigma_{\mathrm{vo}}^{\prime}= \\
200 \mathrm{kPa}\end{array}$ & $\begin{array}{l}0.12 \text { (based on CRR } \\
=0.14 \text { for } N=10 \\
\text { cycles in laboratory, } \\
\text { converted to } N=15 \\
\text { cycles) }\end{array}$ & & \\
\hline
\end{tabular}

Note: Magnitude $(M)=7.5$ is equivalent to 15 cycles of uniform loading.

* CTX, cyclic biaxial; CSS, cyclic simple shear.

${ }^{+}$Numbers are average values in the target zone, with standard deviations in parentheses.

${ }^{\star}$ For samples with $S_{r}=100 \%$, values are averages only (only two such samples for each site).

Phase I and phase IV: CRR values have been calculated from $\mathrm{CRR}_{\mathrm{tx}}$ using $C_{\mathrm{r}}=0.70$ and 0.55 , respectively.

Correction for high overburden stress, $K_{\sigma}=0.76$ (based on laboratory initial isotropic effective stresses for each test of approximately $330 \mathrm{kPa}$ ).

used to estimate state parameter. The method proposed by $\mathrm{Yu}$ et al. involves combining pressuremeter data and CPT data to estimate state parameter.

Wride et al. $(2000 \mathrm{~b})$ provided a detailed discussion of the evaluation of $\Psi$ from the pressuremeter and showed that the Yu et al. (1996) relationship underpredicts the $\Psi$ of the sand (i.e., predicts a denser state) compared with frozen samples.

\section{Cyclic liquefaction}

Much of the early work related to earthquake-induced soil liquefaction resulted from laboratory testing of reconstituted samples subjected to cyclic loading by means of cyclic triaxial, cyclic simple shear, or cyclic torsional tests. The outcome of these studies generally confirmed that the resistance to cyclic loading is influenced primarily by the state of the soil (i.e., void ratio, effective confining stresses, and soil structure) and the intensity and duration of the cyclic loading (i.e., cyclic shear stress and number of cycles), as well as the grain characteristics of the soil. Soil structure incorporates features such as fabric, age, and cementation. Grain characteristics incorporate features such as grain-size distribution, grain shape, and mineralogy.

In situ testing can be used as a simple, economic method of estimating the cyclic resistance of a soil. Various methods have been developed for estimating cyclic resistance from the SPT (Seed et al. 1985), CPT (Olsen and Koester 1995; Robertson and Campanella 1985; Suzuki et al. 1995a, 1995b; Stark and Olson 1995; Robertson and Wride 1998a, 1998b), and $V_{s}$ measurements (Robertson et al. 1992; Andrus and Stokoe 1998). The following sections compare the in situ data from the SPTs and seismic CPTs at each CANLEX site with the cyclic resistance ratio (CRR) observed in the laboratory for undisturbed samples from each site. Table 6 summarizes the results of laboratory testing on ground-freezing samples from each of the six CANLEX sites.
Resistance to cyclic loading is usually represented in terms of a cyclic stress ratio or cyclic resistance ratio (CRR). For cyclic simple shear (CSS) tests, $\mathrm{CRR}_{\mathrm{ss}}$ is taken as the ratio of the cyclic shear stress to cause cyclic liquefaction to the initial vertical effective stress, i.e., $\mathrm{CRR}_{\mathrm{ss}}=\tau_{\mathrm{cyc}} / \sigma_{\mathrm{yi}}^{\prime}$. For cyclic triaxial tests $(\mathrm{CTX}), \mathrm{CRR}_{\mathrm{tx}}$ is taken as the ratio of the maximum cyclic shear stress to cause cyclic liquefaction to the initial effective confining stress, i.e., $\operatorname{CRR}_{\mathrm{tx}}=\sigma_{\mathrm{dc}} /\left(2 \sigma_{3 \mathrm{c}}^{\prime}\right)$. These two tests impose different loading conditions, and the CRR values are not equivalent. Cyclic simple shear tests are generally considered to be more representative of earthquake loading for level ground conditions. At the phase I and phase IV sites, the equivalent $\mathrm{CRR}_{\mathrm{ss}}$ values have been calculated from $\mathrm{CRR}_{\mathrm{tx}}$ using correction factors $C_{\mathrm{r}}=0.70$ and 0.55 , respectively. The CRR was taken at 15 cycles of uniform loading to represent an equivalent earthquake loading of magnitude $(M)$ 7.5. Cyclic liquefaction was taken as the point at which samples experienced large uncontrolled deformations, which was close to the condition of zero effective stress.

Not all sites had sand that was saturated in situ below the groundwater table. The sands from phase I (Mildred Lake) and phase IV (LL Dam) were not saturated. This was likely due to gas generation from residual bitumen at the Mildred Lake site and the recent depositional environment at the LL Dam site. The lack of $100 \%$ saturation in samples complicated the thaw-consolidation process and the interpretation of the test results. Hence, only results on saturated samples were applied, as shown in Table 6.

\section{Standard penetration test (SPT)}

Seed (1979) developed a method to estimate the CRR for a sand under level ground conditions, based on the SPT, which was later modified by Seed et al. (1985). This method was based on extensive field performance data for Holocene sands from essentially level ground sites which either had or 
Fig. 3. Laboratory CRR versus $(a)$ measured SPT $\left(N_{1}\right)_{60}$ and $(b)$ equivalent clean sand SPT $\left(N_{1}\right)_{60 c s}$, using the method suggested by Seed et al. (1985) to estimate the required correction for fines content. Values are averages \pm one standard deviation, and only the results of samples with $S_{\mathrm{r}} \approx 100 \%$ are shown. HM, Highmont.

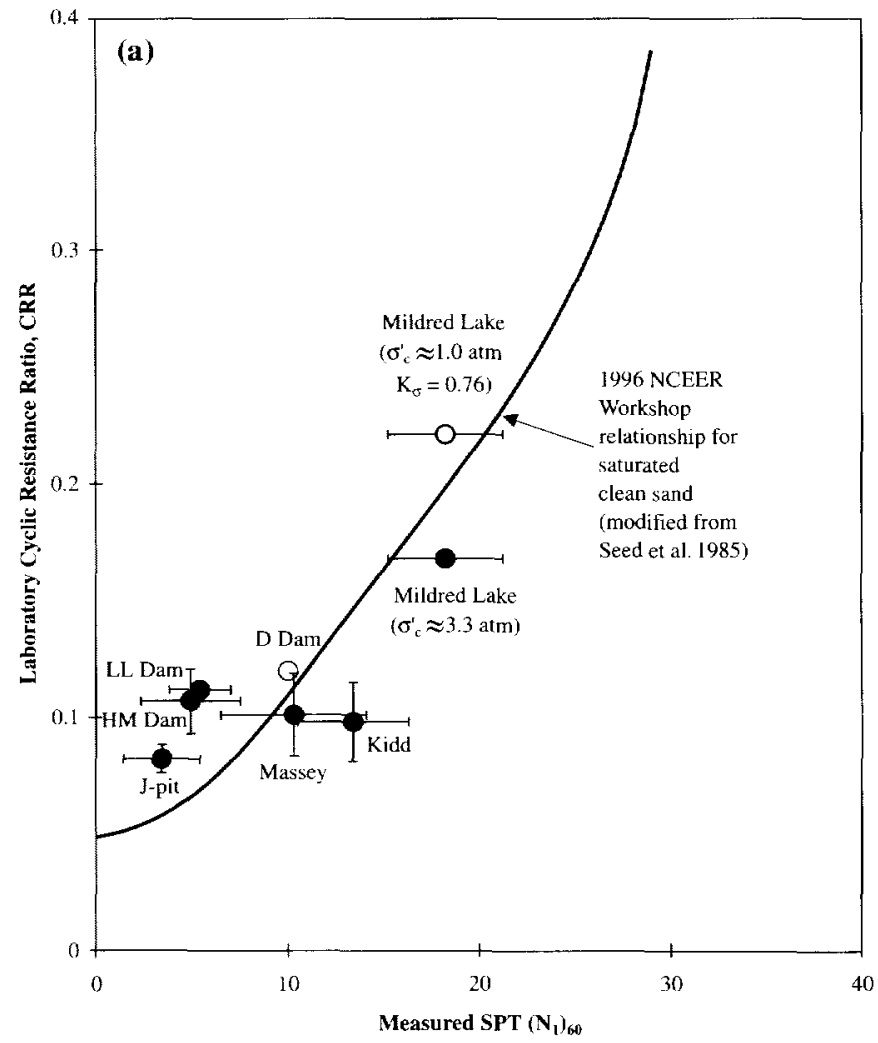

had not experienced cyclic softening (liquefaction) due to earthquake loading. The data were primarily for magnitude 7.5 earthquakes, depth ranges of $1-14 \mathrm{~m}(90 \%$ of data was for depths $<10 \mathrm{~m}$ ), and representative average SPT $N$ values for the layer that was considered to have experienced cyclic liquefaction. Liquefaction was assumed to have occurred based on the presence of observable surface features such as sand boils and ground cracks. Other SPT-based methods have been developed (Tatsuoka et al. 1980; Shibata 1981; Tokimatsu and Yoshimi 1983; Kokusho et al. 1983; Ishihara 1993; Fear and McRoberts 1995), but the correlation by Seed et al. appears to maintain the most popularity, especially in North America. Based on discussions at the 1996 National Center for Earthquake Engineering Research (NCEER) workshop (Youd and Idriss 1997), the Seed et al. SPT curve was slightly modified to avoid extrapolation to zero CRR at zero penetration resistance.

Seed et al. (1985) showed that for a given CRR, a sand with fines has a lower SPT $\left(N_{1}\right)_{60}$ value and, based on this observation, developed the correlation further to include the influence of fines content. The correlation showed that, for the same CRR, the penetration resistance in silty sands was smaller. This is most likely due to the greater compressibility and decreased permeability of silty sands which reduce penetration resistance and move the penetration process toward an undrained penetration. Although the original correlations were based on fines content, it is clear that the CRR of a soil is a function of many factors, including type of fines, e.g., plasticity, other grain characteristics (mineralogy,

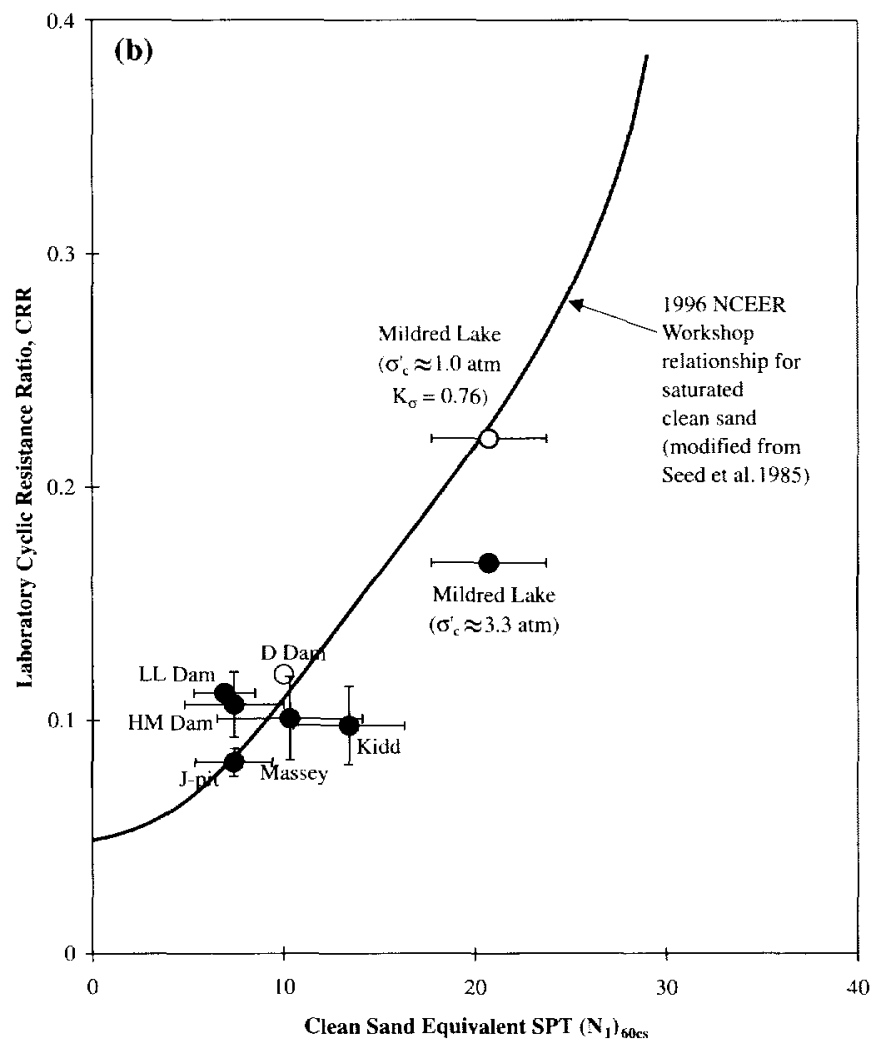

grain shape, etc.), and fines content (FC). Seed et al. suggested an FC-dependent correction factor, $\Delta\left(N_{1}\right)_{60}$ which could be added to the measured $\left(N_{1}\right)_{60}$ to obtain a clean sand equivalent penetration resistance, $\left(N_{1}\right)_{60 \mathrm{cs}}$. These corrections were used to calculate $\left(N_{1}\right)_{60 \text { s }}$ values for the CANLEX sites.

Figure 3 compares the CANLEX and Duncan Dam data with the relationship between CRR and $\left(N_{1}\right)_{60 \mathrm{cs}}$ proposed by the 1996 NCEER workshop. In Fig. $3 a$, the SPT data have been plotted in terms of the measured $\left(N_{1}\right)_{60}$, with no correction for fines content. In Fig. $3 b$, the SPT data have been corrected to clean sand equivalent values of $\left(N_{1}\right)_{60 \mathrm{cs}}$ using the corrections recommended by Seed et al. (1985), based on the overall approximate fines content for each site (as given by Robertson et al. 2000). Since Duncan Dam is essentially a clean sand, no correction was applied to the Duncan Dam datapoint. The data are shown in terms of average values plus and minus one standard deviation. Only the results from samples with a degree of saturation $S_{\mathrm{r}} \approx 100 \%$ are shown; some phase I and LL Dam samples had $S_{\mathrm{r}}<100 \%$ and slightly higher values of CRR measured in the laboratory.

In general, the data corrected for fines content fit the Seed et al. (1985) curve better than the measured values with no correction. There appears to be no clear trend due to factors such as age, although Kidd is the oldest deposit and plots with a higher $\left(N_{1}\right)_{60}$. Seed and Harder (1990) suggested a correction factor, $K_{\sigma}$, to account for a reduced CRR under high effective overburden stress. Since the average effective overburden stress $\left(\sigma_{y}^{\prime}\right)$ for each site except Mildred Lake is close to $100 \mathrm{kPa}$ (see Table 1), no correction has been made. 
For Mildred Lake, the average vertical effective stress, $\sigma_{v}^{\prime}$, in the target zone was about $500 \mathrm{kPa}$. Assuming a $K_{0}$ of 0.5 , the average mean normal effective stress, $p^{\prime}$, in the phase I target zone was about $330 \mathrm{kPa}$. The cyclic triaxial tests on phase I samples were conducted under initial isotropic effective stresses of about $330 \mathrm{kPa}$ so that the samples were loaded under approximately the same $p^{\prime}$ as existed in situ. When the measured average CRR for the Mildred Lake samples is corrected for the high laboratory effective stress using $K_{\sigma}=0.76$ (the value recommended by NCEER for an effective confining pressure of $330 \mathrm{kPa}$ ), the agreement with the NCEER SPT-based curve is very good. This adds support to the $K_{\sigma}$ correction for high overburden stress.

Since the SPT at the Mildred Lake site was carried out at depths from 27 to $37 \mathrm{~m}$, there is greater uncertainty over the measured blow counts due to long rod length.

\section{Cone penetration test (CPT)}

Several correlations have been proposed to estimate CRR for clean sands and silty sands using corrected CPT penetration resistance (e.g., Robertson and Campanella 1985; Seed and de Alba 1986; Olsen 1988; Olsen and Malone 1988; Shibata and Teparaska 1988; Mitchell and Tseng 1990; Olsen and Koester 1995; Suzuki et al. 1995a, 1995b; Stark and Olson 1995; Robertson and Fear 1995; Robertson and Wride $1998 a, 1998 b$ ). In recent years there has been an increase in available field-performance data for the CPT (Ishihara 1993; Kayen et al. 1992; Stark and Olson 1995; Suzuki et al. $1995 \mathrm{~b}$ ). These data have shown that the existing CPTbased correlations for estimating CRR are generally good for clean sands and that the correlation between CRR and $q_{\mathrm{cIN}}$ by Robertson and Campanella (1985) for clean sands provides a reasonable estimate of CRR. The field data are primarily for Holocene-age, clean sand deposits, in level or gently sloping ground, with a depth range of $1-15 \mathrm{~m}(84 \%$ of data was for depths $<10 \mathrm{~m}$ ) and representative average CPT $q_{c}$ values for the layer that was considered to have experienced cyclic liquefaction. Based on discussions at the 1996 NCEER workshop (Youd and Idriss 1997), the curve by Robertson and Campanella has been adjusted slightly at the lower end to be more consistent with the SPT curve. Robertson and Wride (1998a, 1998b) define the normalized cone resistance, $\left(q_{\mathrm{c} 1 \mathrm{~N}}\right)$, as follows:

$$
\left(q_{\mathrm{c} 1 \mathrm{~N}}\right)=\left(\frac{q_{\mathrm{c}}}{P_{\mathrm{a}}}\right)\left(\frac{P_{\mathrm{a}}}{\sigma_{\mathrm{v}}^{\prime}}\right)^{0.5}
$$

\section{where}

$q_{\mathrm{c}}$ is the measured cone resistance;

$\sigma_{v}^{\prime}$ is the vertical effective stress; and

$P_{\mathrm{a}}$ is the atmospheric pressure $(100 \mathrm{kPa})$.

Although the CPT does not provide samples for direct determination of fines content, it is possible to estimate grain characteristics from CPT data and incorporate this directly into the evaluation of liquefaction potential. Various researchers (see earlier in the paper) have developed methods for estimating these grain characteristics.

Figure 4 compares the CANLEX $\left(S_{\mathrm{r}}=100 \%\right)$ and Duncan Dam data with the relationship between CRR and the clean sand equivalent normalized cone resistance $\left(q_{\mathrm{clN}}\right)_{\mathrm{cs}}$, as pro- posed by Robertson and Wride (1998a). In Fig. 4a, the CPT data have been plotted in terms of the measured $q_{\mathrm{clN}}$, with no correction for grain characteristics. In Fig. 4b, the CPT data have been corrected to clean sand equivalent values of $\left(q_{\mathrm{c}, \mathrm{v}}\right)_{\mathrm{cs}}$ using the method recommended by Robertson and Wride.

In general, the data corrected for grain characteristics fit the Robertson and Wride (1998a, 1998b) curve slightly better than the measured values with no correction. There appears to be no trend due to factors such as age. When the measured CRR for Mildred Lake is corrected for the high overburden stress using $K_{\sigma}=0.76$ (based on a laboratoryapplied isotropic effective stress of $330 \mathrm{kPa}$ ), the agreement with the NCEER curve is not quite as good, although the CRR- $q_{\mathrm{cIN}}$ relationship varies rapidly when $q_{\mathrm{clN}}>100$.

\section{Cyclic resistance from shear wave velocity}

Several methods for evaluating cyclic liquefaction potential based on shear wave velocity measurements have also been developed (Stokoe et al. 1988; Tokimatsu et al. 1991; Robertson et al. 1992; Kayen et al. 1992; Andrus 1994; Lodge 1994). Recently, as part of the 1996 NCEER workshop on liquefaction, the relationship proposed by Andrus and Stokoe (1998) was recommended.

Figure 5 compares the CANLEX $\left(S_{\mathrm{r}}=100 \%\right)$ and Duncan Dam data with the relationship between CRR and $V_{s 1}$ as proposed by Andrus and Stokoe (1998). The CANLEX data are shown in terms of average values plus and minus one standard deviation. In general, the data fit the Andrus and Stokoe (1998) curve fairly well. The two older sites (Duncan Dam and Kidd), for which age is $\geq 4000$ years, appear to fit below the relationship, whereas the younger sites fit above the relationship. Hence, the shear wave velocity relationship for CRR may be slightly influenced by the age of the deposit. When the Mildred Lake CRR is corrected for the high overburden stress, the agreement with the NCEER curve is not as good. Hence, it appears that the overburden correction $\left(K_{\sigma}\right)$ may not apply equally to the $V_{\mathrm{s}}$ and CPT-CRR curves as for the SPT curves. Also the shear wave velocity measurements were less accurate at the Mildred Lake site due to large depth $(>30 \mathrm{~m})$.

\section{Flow liquefaction}

Depending on the nature of the project, different levels of information may be required for a flow liquefaction analysis. For some projects, the information required may be the expected large strain (residual) undrained shear strength for application into a limit equilibrium stability analysis. For other projects, the complete stress-strain curves of the soil may be required for application into a more comprehensive deformation numerical analysis (Byrne et al. 2000).

There is extensive evidence to show that the undrained response of a sand is a function of the in situ state, anisotropic stress state, and direction of loading. The early work of Been and Jefferies (1985) and Been et al. $(1986,1987)$ showed the importance of defining in situ state in terms of a combination of void ratio and in situ effective confining stress. Hanzawa (1980), Georgiannou et al. (1990), Vaid and Sivathayalan (1996), and Yoshimine (1996) have shown the importance of direction of loading on the undrained response of sand. In particular, Hanzawa and Vaid and Sivathayalan 
Fig. 4. Laboratory CRR versus $(a)$ measured CPT $q_{\mathrm{c} 1 \mathrm{~N}}$ and $(b)$ equivalent clean sand CPT ( $\left.q_{\mathrm{c} N \mathrm{~N}}\right)_{\mathrm{cs}}$, using the method suggested by Robertson and Wride $(1998 a, 1998 b)$ to calculate the clean sand equivalent values. Values are averages \pm one standard deviation, and only the results of samples with $S_{\mathrm{r}} \approx 100 \%$ are shown.

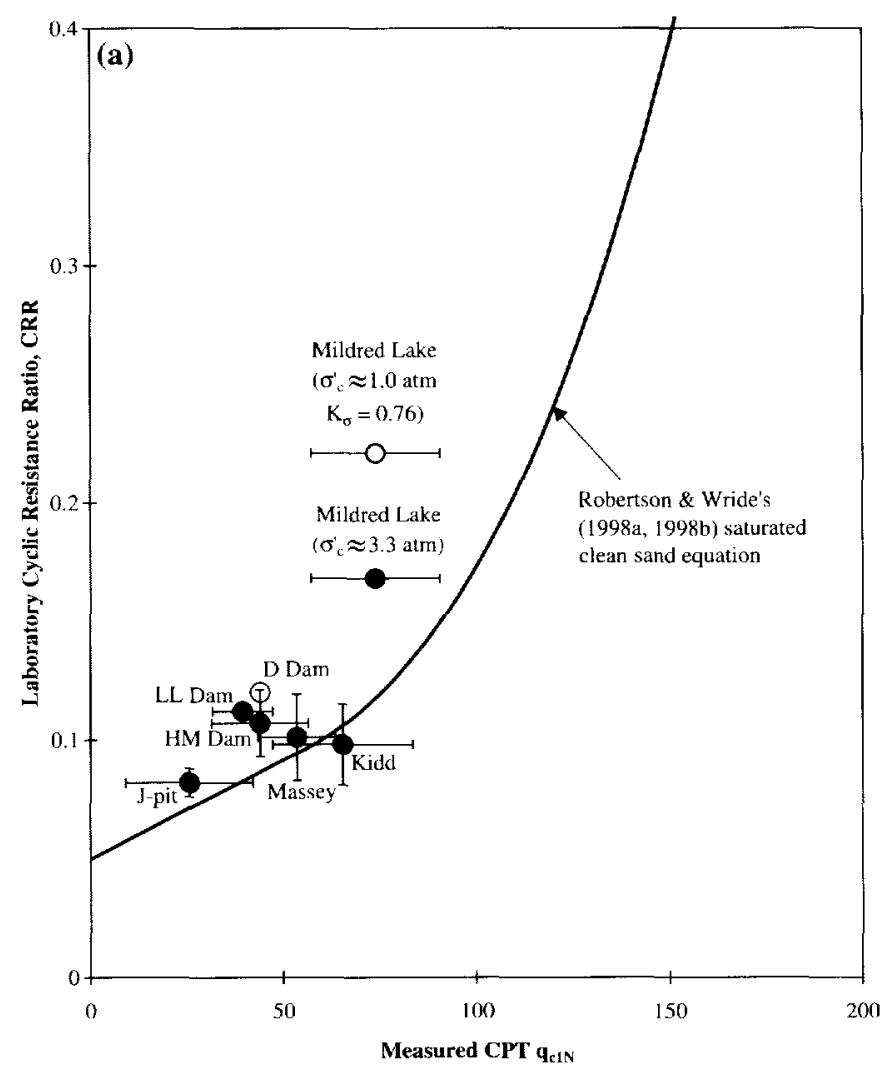

have shown that the minimum undrained shear strength $\left(S_{\text {min }}\right)$ is significantly smaller in triaxial extension (TE) than in triaxial compression (TC). Simple shear (SS) loading was generally intermediate between compression and extension loading. This is consistent with the response observed for clays (Bjerrum 1972; Jamiolkowski et al. 1985).

\section{Range of response to undrained loading}

When sandy soils are subjected to monotonic undrained loading, a range of responses is possible. This range in possible responses is illustrated in Fig. 6. Four idealized stressstrain curves are shown, identified as A, B, C, and D. Each line represents a sample subjected to an anisotropic initial stress state (i.e., initial shear stress $>0$ or $K_{0}<1$ ). Lines A and $B$ follow the type $A$ and type $B$ classification of the undrained response of sandy soils, as proposed by Hanzawa (1980). Line A represents the weakest type of response in which, when loaded undrained, the sample reaches a peak strength and then completely strain softens to a minimum strength at ultimate state. Line $D$ represents the strongest type of response in which, when loaded undrained, the sample continues to strain harden throughout the test, eventually reaching a much larger strength at ultimate state.

Lines $B$ and $C$ represent the two types of intermediate responses. Line B illustrates the type of response associated with limited strain softening; the sample reaches a peak strength and then strain softens to a quasi steady state (QSS) or minimum strength $\left(S_{\min }\right)$ during which a certain amount of strain occurs. However, the sample then strain hardens to

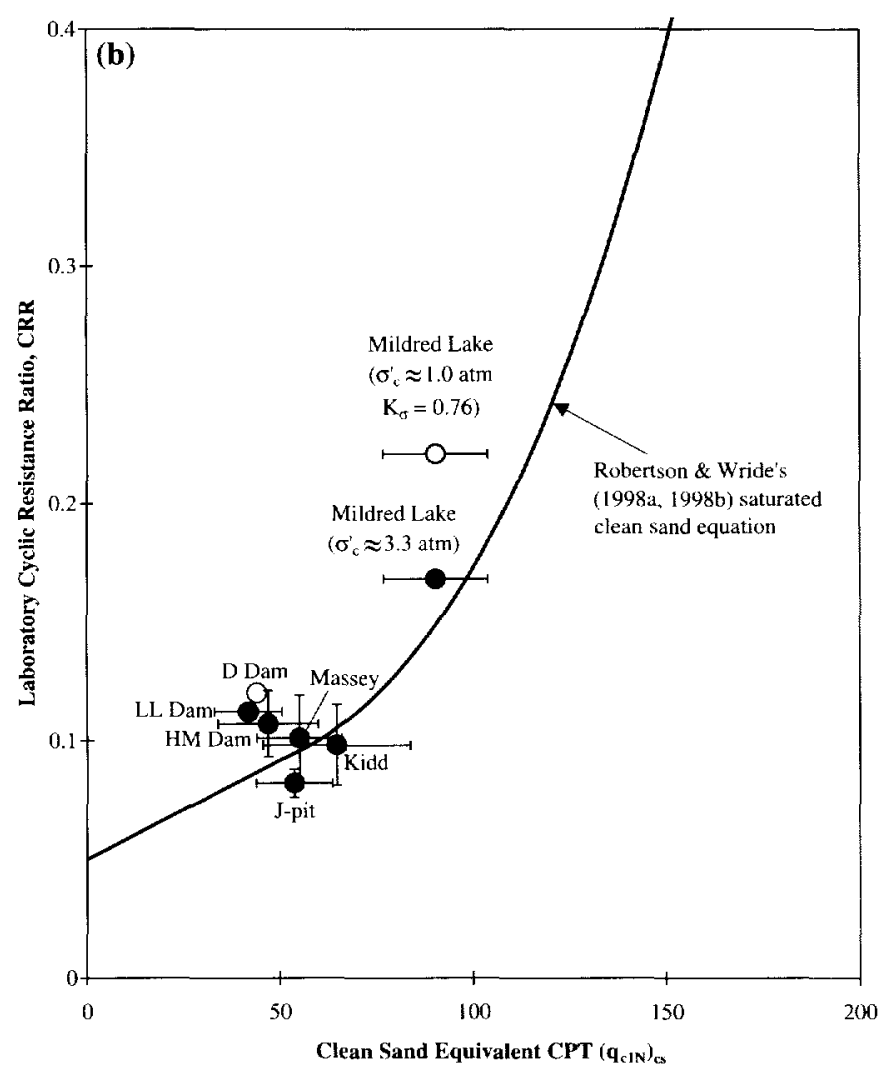

its ultimate state. Line C illustrates a fourth type of response that may be observed; the sample continually strain hardens throughout the test and never strain softens, even temporarily. However, once the initial peak strength is reached, the stress-strain curve experiences a plateau during which a certain amount of strain occurs without any increase or loss in strength; the sample then continues to strain harden to its ultimate state.

The key distinguishing features between lines A, B, C, and $D$ are the undrained shear strength reached at intermediate and large strain and the brittleness of the response. Both lines $C$ and $D$ are nonbrittle, in that no loss of strength is ever observed, even temporarily. Line $\mathrm{A}$ is brittle, in that a large amount of strength is lost after the peak strength is reached and is never recovered; the resulting ultimate undrained shear strength is often very small. Samples that exhibit a response similar to that of line $B$ may have a range of brittleness, depending if the response is closer to the type $A$ response or the type $\mathrm{C}$ response. In all cases, the loss in strength may be temporary and a certain amount of strength can be ultimately regained. However, the more brittle the type $B$ response is, the more important a role the QSS or minimum undrained shear strength may play.

In all cases, one would expect the stress-strain curve to eventually level off as ultimate state is approached. However, in general, the level of strain required to reach ultimate state often exceeds the capabilities of the laboratory equipment. Thus, lines B, C, and D in Fig. 6 are shown to be climbing towards their ultimate state. The "end-of-test" point 
Fig. 5. Laboratory CRR versus measured shear wave velocity, $V_{\mathrm{s} 1}$. Values are averages \pm one standard deviation, and only the results of samples with $S_{\mathrm{r}} \approx 100 \%$ are shown.

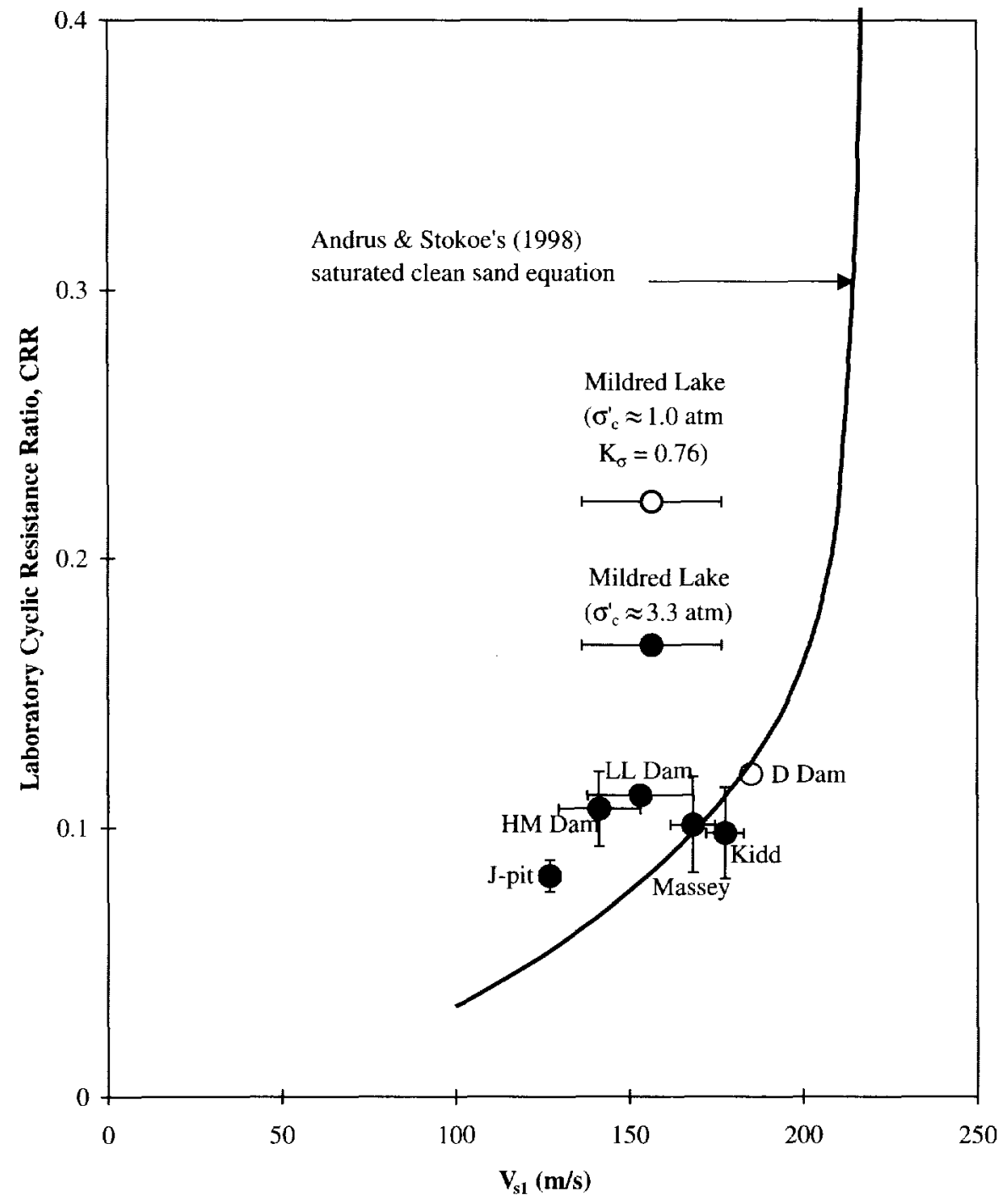

for each CANLEX test was used in the subsequent analysis; depending on the particular test, this was generally not coincident with the ultimate state. The end-of-test condition generally occurred at a strain level between 15 and $20 \%$.

Whether a sample will respond similarly to line A, B, C, or $\mathrm{D}$ depends on several factors, including the initial state of the sample (in terms of both void ratio and initial stresses) and the direction of loading imposed on the sample (e.g., triaxial compression, triaxial extension, or simple shear). Whether a sample is loaded in a stress-controlled or a straincontrolled manner may also affect the undrained response, especially for type $B$ response where the sample may not strain harden in stress-controlled loading (Hanzawa 1980). All of the CANLEX samples were subjected to straincontrolled tests. The stress-strain curves generated by the CANLEX project during laboratory testing will be classified in terms of the four lines presented in Fig. 6.

\section{CANLEX laboratory data}

Table 7 summarizes the results of laboratory testing on ground-freezing samples from each of the six CANLEX sites. A total of 106 ground-freezing samples were tested in monotonic undrained shear, 51 in triaxial compression, 23 in simple shear, and 32 in triaxial extension. As noted in $\mathrm{Ta}-$ ble 7 , most of these samples $(66 \%)$ strain hardened when subjected to undrained loading (type D response). Only some samples $(23 \%)$ demonstrated limited strain softening, first strain softening to a minimum strength at QSS before strain hardening towards their ultimate states (type B response). Overall, approximately $8 \%$ of the triaxial compression samples, $30 \%$ of the simple shear samples, and $41 \%$ of the triaxial extension samples exhibited a type $B$ response. None of the samples strain softened directly to ultimate state (type A response), although two of the type $B$ responses were very brittle and thus close to a type $A$ response. A few samples (11\%) exhibited a plateau in their strain-hardening behaviour (type $\mathrm{C}$ response).

The average QSS parameters (minimum undrained strength, strength ratio, brittleness, and sensitivity) for the samples from each site which experienced type $B$ responses are summarized in Table 8 . The average plateau parameters (undrained strength and strength ratio at the plateau) for the 
Fig. 6. Range of possible responses (A-D) to undrained monotonic shear loading of sandy soils in the laboratory.

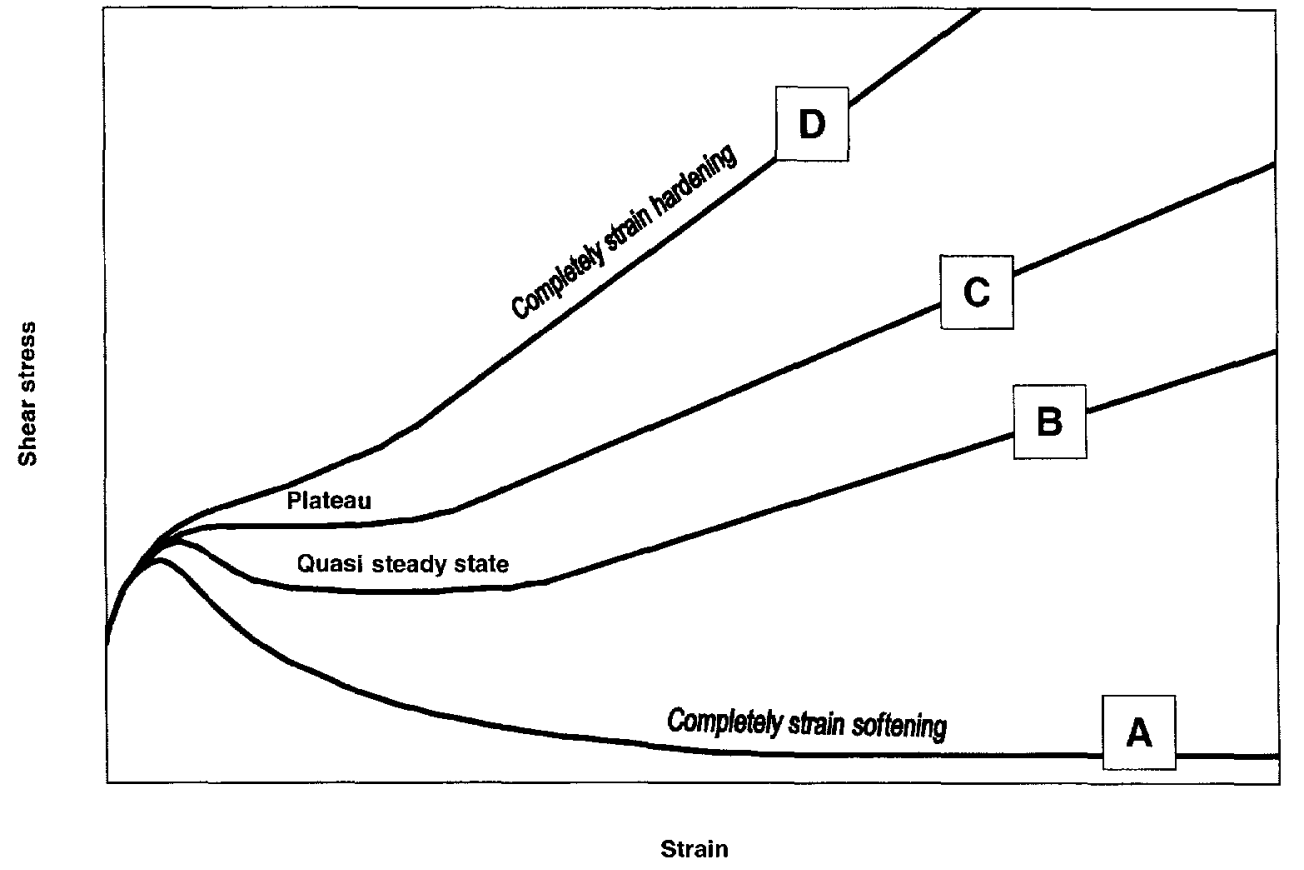

few samples from each site which experienced type $C$ responses are summarized in Table 9 . In both tables, $p_{i}^{\prime}$ for simple shear tests was estimated from $\sigma_{\mathrm{vi}}^{\prime}$ using $K_{0}=0.5$; for triaxial tests, $p_{i}^{\prime}$ is the value measured in the test.

Table 10 summarizes the average end-of-test responses, based on all of the samples from each site which were tested (types B, C, and D). In Table $10, p_{\mathrm{i}}^{\prime}$ for simple shear tests was estimated from $\sigma_{\mathrm{vi}}{ }^{\prime}$ using $K_{0}=0.5$; for triaxial tests, $p_{\mathrm{i}}^{\prime}$ is the value measured in the test. It is important to note that all of the triaxial extension tests were still strain hardening at the end of the test and several failed in necking; thus the end-of-test point is likely significantly below the possible ultimate state.

\section{Monotonic response in terms of state}

The primary parameters for defining the state of sand are relative density $\left(D_{\mathrm{r}}\right)$ and state parameter $(\Psi)$. The calculation of relative density requires values of $e_{\max }$ and $e_{\min }$. Representative values of these index parameters are given in Table 2. For some of the CANLEX sands, small variations in grain characteristics made the determination of these representative index parameters somewhat uncertain and hence the determination of relative density somewhat uncertain. The Syncrude sand (phases I and III) was particularly difficult to test, with a wide range in index parameters, as illustrated by the difference between phase I and phase III values.

Figure $7 a$ presents a plot of minimum undrained strength ratio $\left(S_{\min } / p^{\prime}\right)$ versus relative density based on data from Yoshimine (1996) and Verdugo (1992) on Toyoura sand and Yoshimine et al. (1999) on Kawagishi-cho sand. Toyoura and Kawagishi-cho sands are both clean, uniformly graded, quartz sands with rounded grains. The results are limited to samples that experienced strain softening in undrained shear (type $\mathrm{A}$ and type $\mathrm{B}$ responses). These samples had an initial mean effective stress less than $500 \mathrm{kPa}$ and were tested under isotropic initial stress states for both TC and TE.

Figure $7 a$ shows a reasonably consistent set of responses, regardless of the mode of deposition, with the undrained strength ratio being significantly larger in triaxial compression than in triaxial extension. This result is consistent with previous observations for clay soils (Bjerrum 1972) and recent observations for reconstituted sands (Hanzawa 1980; Georgiannou et al. 1990; Yoshimine 1996; Vaid and Sivathayalan 1996). Generally, larger inclinations of the maximum principal stress from the vertical to the bedding plane and larger intermediate principal stresses make the behaviour weaker. Figure $7 a$ clearly shows the importance of the mode of shear during undrained shearing of sands.

Figure $7 b$ shows a summary of the test results on 87 reconstituted samples of the three CANLEX sands in terms of the minimum undrained strength ratio $\left(S_{\min } / p^{\prime}\right)$ versus relative density for samples that showed a strain-softening (types A or B) response. The trend lines from Fig. 7a, as proposed by Yoshimine et al. (1999), are shown for comparison. The CANLEX data are quite limited and are dominated by tests on Syncrude sand $(84 \%)$. The samples were prepared using a variety of methods of preparation (moist tamping $50 \%$, air pluviation $23 \%$, and water pluviation $27 \%$ ). In addition, approximately half of the samples were isotropically consolidated $\left(K_{0}=1.0\right)$, and the remainder were anisotropically consolidated to a $K_{0}$ of about 0.5 . The majority of the samples had an initial mean normal effective stress, $p_{i}^{\prime}$, less than $500 \mathrm{kPa}$; however, eight samples had values of $p_{i}^{\prime}$ slightly greater than $500 \mathrm{kPa}$. The strength ratio was selected as the representative response, since most of the samples showed a quasi-steady-state (type B) response; some samples showed a type A response.

The reconstituted test results on the CANLEX sands shown in Fig. $7 b$ show somewhat similar trends to those of 


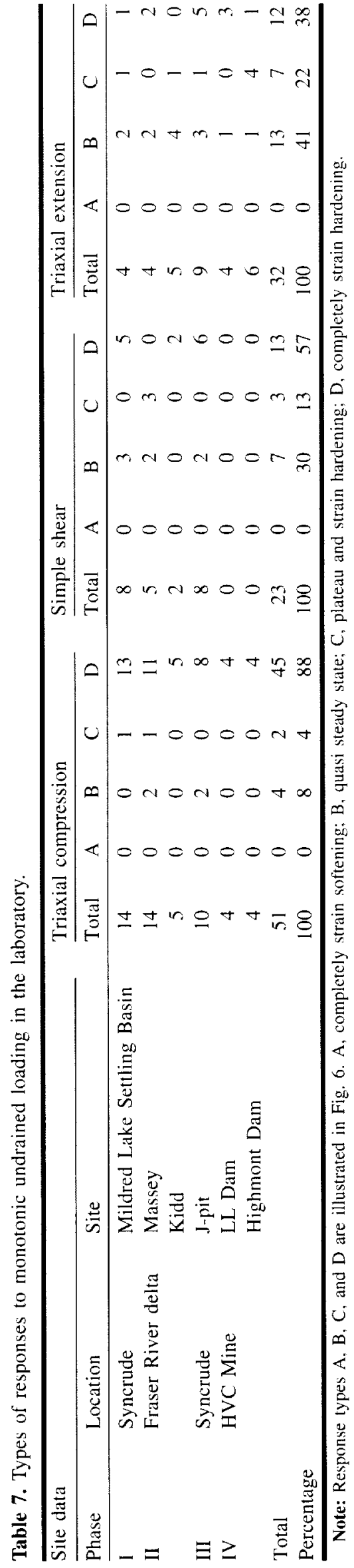

Toyoura and Kawagishi-cho sands in Fig. 7a, although there is considerably more scatter in the CANLEX results. The increased scatter may be due, in part, to the variations in grain characteristics within each deposit, resulting in some uncertainty in calculated relative density. Also, the larger variation may be due, in part, to the different modes of deposition and initial $K_{0}$ conditions. Much of the reconstituted testing ( $84 \%$ ) was carried out on Syncrude sand (phases I and III), which was sensitive to the mode of deposition, and $50 \%$ of the testing was carried out under anisotropic initial stress states $\left(K_{0}=0.5\right)$.

Figure 8 shows the same data in terms of brittleness index and minimum undrained strength ratio $\left(S_{\min } / p^{\prime}\right)$. Brittleness index (Bishop 1967) is an index of the collapsibility of a strain-softening soil when sheared undrained and is defined as follows:

$$
I_{\mathrm{B}}=\frac{S_{\mathrm{p}}-S_{\min }}{S_{\mathrm{p}}}
$$

where $S_{\mathrm{p}}$ is the peak shear resistance prior to strain softening, and $S_{\min }$ is the minimum undrained shear strength. A value of $I_{\mathrm{B}}=1$ indicates zero minimum undrained shear strength. If there is no strain softening (types $\mathrm{C}$ or $\mathrm{D}$ responses), then $I_{\mathrm{B}}=0$.

Figure 8 shows a link between the response characteristics of brittleness and minimum undrained strength ratio with only a small influence of direction of loading. As expected, when the minimum undrained strength ratio decreases, the brittleness increases. The sands are essentially nonbrittle $\left(I_{\mathrm{B}}=0\right)$ when the minimum undrained strength ratio $\left(S_{\min } / p^{\prime}\right)$ is greater than about 0.2 for TE, 0.25 for SS, and 0.40 for TC. These values are similar to those observed for fine-grained (clay) soils of low plasticity (Jamiolkowski et al. 1985).

The reconstituted CANLEX sands appear to be somewhat less brittle than Toyoura sand in TE and slightly more brittle than Toyoura sand in TC. This may be due to the fact that the Toyoura sand results were for isotropically consolidated samples, whereas approximately half of the CANLEX reconstituted samples were anisotropically consolidated $\left(K_{0}=0.5\right)$.

Figure 9 shows the same data in terms of minimum strength ratio versus state parameter. Similar trends are $o b-$ served, although the agreement between the CANLEX results and the trends for Toyoura sand are generally better than those based on relative density.

Figure $10 a$ shows the minimum undrained shear strength ratio for the undisturbed samples from the CANLEX sites for which strain softening was observed (type B response) plotted against relative density for each sample. The trend lines from the reconstituted Toyoura sand samples are also shown as a reference for comparison. In general, there is reasonable agreement between the results of the tests on undisturbed samples and the trends from reconstituted samples. The exceptions are the results for the samples from the phase I site (Mildred Lake) for which the stress level is around $500 \mathrm{kPa}$ and the phase IV sites (LL Dam and Highmont Dam) which had more angular grains. High stress levels appear to reduce the undrained strength ratio at a constant relative density (Yoshimine et al. 1999), similar to the effect observed for cyclic resistance ratio (CRR). The more 

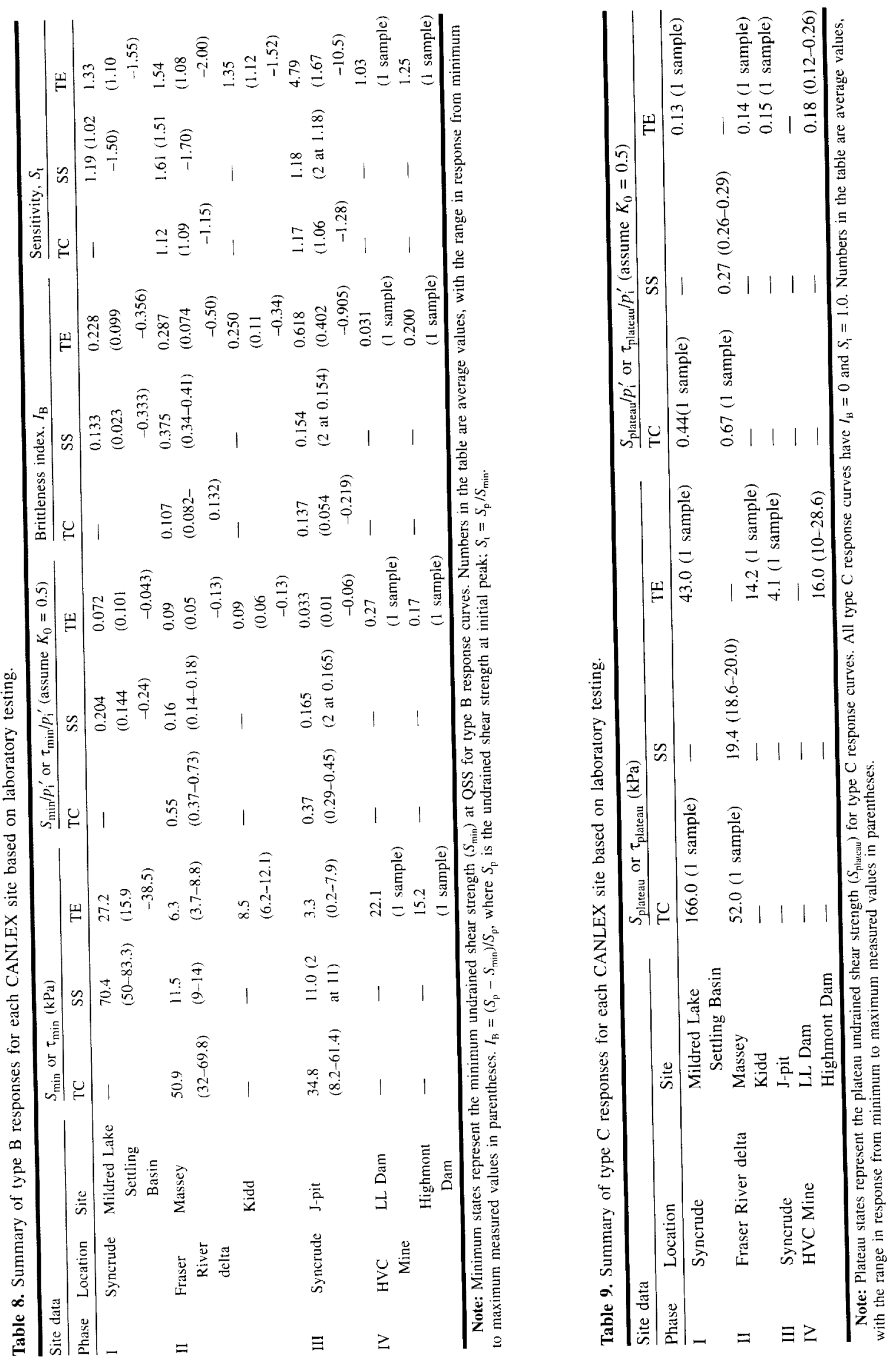

(1) 2000 NRC Canada 
Table 10. Summary of end-of-test states for all undisturbed samples (types B, C, and D combined).

\begin{tabular}{|c|c|c|c|c|c|c|c|c|}
\hline \multicolumn{3}{|c|}{ Site data } & \multicolumn{3}{|l|}{$S_{\mathrm{f}}$ or $\tau_{\mathrm{f}}(\mathrm{kPa})$} & \multicolumn{3}{|c|}{$\mathrm{S}_{\mathrm{f}} / p_{\mathrm{i}}^{\prime}$ or $\tau_{\mathrm{f}} / p_{\mathrm{i}}^{\prime}\left(\right.$ assume $K_{0}=0.5$ ) } \\
\hline Phase & Location & Site & TC & SS & TE & $\mathrm{TC}$ & SS & $\mathrm{TE}$ \\
\hline I & Syncrude & $\begin{array}{l}\text { Mildred Lake } \\
\text { Settling Basin }\end{array}$ & $686.0(197.4)$ & $190(67.7)$ & $127.4(9.6)$ & $2.12(0.76)$ & $0.55(0.20)$ & $0.37(0.06)$ \\
\hline \multirow[t]{2}{*}{ II } & Fraser River delta & Massey & $237.8(128.2)$ & $27.5(11.7)$ & $47.6(21.3)$ & $3.34(2.09)$ & $0.39(0.18)$ & $0.61(0.24)$ \\
\hline & & Kidd & $318.3(87.1)$ & $154.0(15.2)$ & $65.0(20.4)$ & $3.52(1.33)$ & $1.94(0.19)$ & $0.71(0.32)$ \\
\hline III & Syncrude & J-pit & $175.9(62.2)$ & 一 & $51.0(56.7)$ & $4.00(2.29)$ & - & $0.76(0.58)$ \\
\hline \multirow[t]{2}{*}{ IV } & HVC Mine & LL Dam & $151.7(13.0)$ & - & $51.8(28.6)$ & $2.13(0.38)$ & - & $0.84(0.46)$ \\
\hline & & Highmont Dam & $206.3(71.5)$ & - & $37.0(14.9)$ & $2.21(0.41)$ & - & $0.42(0.17)$ \\
\hline
\end{tabular}

Note: Numbers in the table are average values in the target zone, with standard deviations in parentheses. $S_{f}$ and $\tau_{f}$ are end-of-test undrained shear strength values.

angular phase IV sand appears to have a higher minimum undrained shear strength for a given relative density, which may explain why no samples from these sites were strain softening in TC or SS.

Figure $10 b$ shows the measured brittleness index values versus minimum undrained strength ratio $\left(S_{\min } / p^{\prime}\right)$, and similar trends are seen with the reconstituted samples; again the TE samples are less brittle than the isotropically consolidated Toyoura sand samples. High stress level and grain angularity appear to have little effect on the link between the response characteristics.

Figure 11 shows the results of the same undisturbed CANLEX samples plotted against state parameter. The trend lines from the reconstituted Toyoura sand samples are also shown. In general, there is good agreement between the tests results for undisturbed samples and the trends from reconstituted CANLEX and Toyoura sand samples, except for the more angular phase IV sand, which appears to be stronger. The phase I results show better agreement in terms of state parameter than relative density, which could be expected, since state parameter includes both void ratio and stress level.

It is important to note that only $23 \%$ of all undisturbed samples that were tested exhibited a strain-softening (type B) response. Hence, $77 \%$ of the undisturbed samples that were tested exhibited a stronger response that those shown in Table 8 and Figs. 10 and 11 . This is understandable for the TC and SS directions of loading for which a small increase in relative density or a small decrease in state parameter can produce large increases in minimum undrained strength ratio and, hence, a nonbrittle response.

Comparing the average in situ state of samples (Table 5) with those shown in Figs. 10 and 11 shows that the samples from phase I (Mildred Lake) and phase IV (LL Dam) densified somewhat during thaw and consolidation due to lack of full saturation (Wride and Robertson 1997b, 1997c, $1997 d$ ). Hence, their in situ minimum undrained strength ratio may be somewhat smaller than that shown in Table 8 , although the trend lines shown in Figs. 10 and 11 could be used as a guide to estimate the change in response due to any change in state during thaw and consolidation. The minimum undrained strength and strength ratio values for type $\mathrm{C}$ responses are given in Table 9 . The average end-of-test undrained strength and strength ratio values based on all samples (strongly influenced by values from samples with type D responses) are given in Table 10 . All of these values are significantly higher than those shown in Figs. 10 and 11 .

\section{Monotonic response in terms of in situ tests}

Several published correlations, based on case histories, exist for estimating the undrained (residual) strength $\left(S_{u}\right)$ from the SPT (Seed and Harder 1990; Stark and Mesri 1992). Figure $12 a$ shows the average and standard deviation of corrected SPT blow count $\left(N_{1}\right)_{60}$ from the six CANLEX sites, along with the range of measured minimum undrained shear strength from undisturbed samples $\left(S_{\min }\right)$, which demonstrated a strain-softening (type $B$ ) response. Also included in the plot are the simple shear results from the Duncan Dam study (Little et al. 1994) and the range in $S_{\mathrm{u}}$ recommended by Seed and Harder (1990) for clean sands. Figure $12 b$ shows the average and standard deviation values of equivalent clean sand corrected SPT blow count, $\left(N_{1}\right)_{60 \mathrm{cs}}$, from the six CANLEX sites. The correction to clean sand equivalent was made using the method suggested by Seed et al. (1985) for cyclic liquefaction, based on fines content. Since not all samples that were tested showed a strain-softening (type B) response, it is reasonable to take the average minus one standard deviation value of SPT blow count as a more representative measure of the associated in situ state. However, it may be more representative to take the average value of the SPT for the phase I and LL Dam (phase IV) sites, since those samples showed some densification during thaw and consolidation due to a lack of full saturation. Also, since $\left(N_{1}\right)_{60 \mathrm{cs}}$ correlates with relative density, it is reasonable to assume that the phase I test results may be low due to the high stress level $\left(\sigma_{\mathrm{vi}}^{\prime} \approx 500 \mathrm{kPa}\right)$. The phase IV triaxial extension test results, which were for angular sands, plot significantly higher than the other results on more rounded sands at similar SPT blow counts.

With these observations in mind, it would appear that the triaxial extension results plot close to the lower bound and the simple shear results plot close to the upper bound of the range suggested by Seed and Harder (1990). Above an SPT $\left(N_{1}\right)_{60 \mathrm{cs}}$ of 12 , the laboratory data from Duncan Dam indicate a more rapid increase in shear strength than suggested by Seed and Harder. The range suggested by Seed and Harder significantly underpredicts the undrained strength in triaxial compression loading. The Seed and Harder relationship appears to be conservative, at least for certain types of loading. This is consistent with the findings reported by Wride et al. (1999) after reexamining the case histories in the Seed and Harder database. The undrained strength for angular sands appears to be significantly larger at the same value of $\left(N_{1}\right)_{60 \mathrm{cs}}$. A correction for high overburden stress (similar to $K_{\sigma}$ ) may also be required when estimating the 
Fig. 7. Relationships between relative density and minimum undrained strength ratio for strain-softening samples (type A and B responses): (a) clean sand trend lines proposed by Yoshimine et al. (1999); (b) comparison of CANLEX reconstituted test results with trends observed by Yoshimine et al.
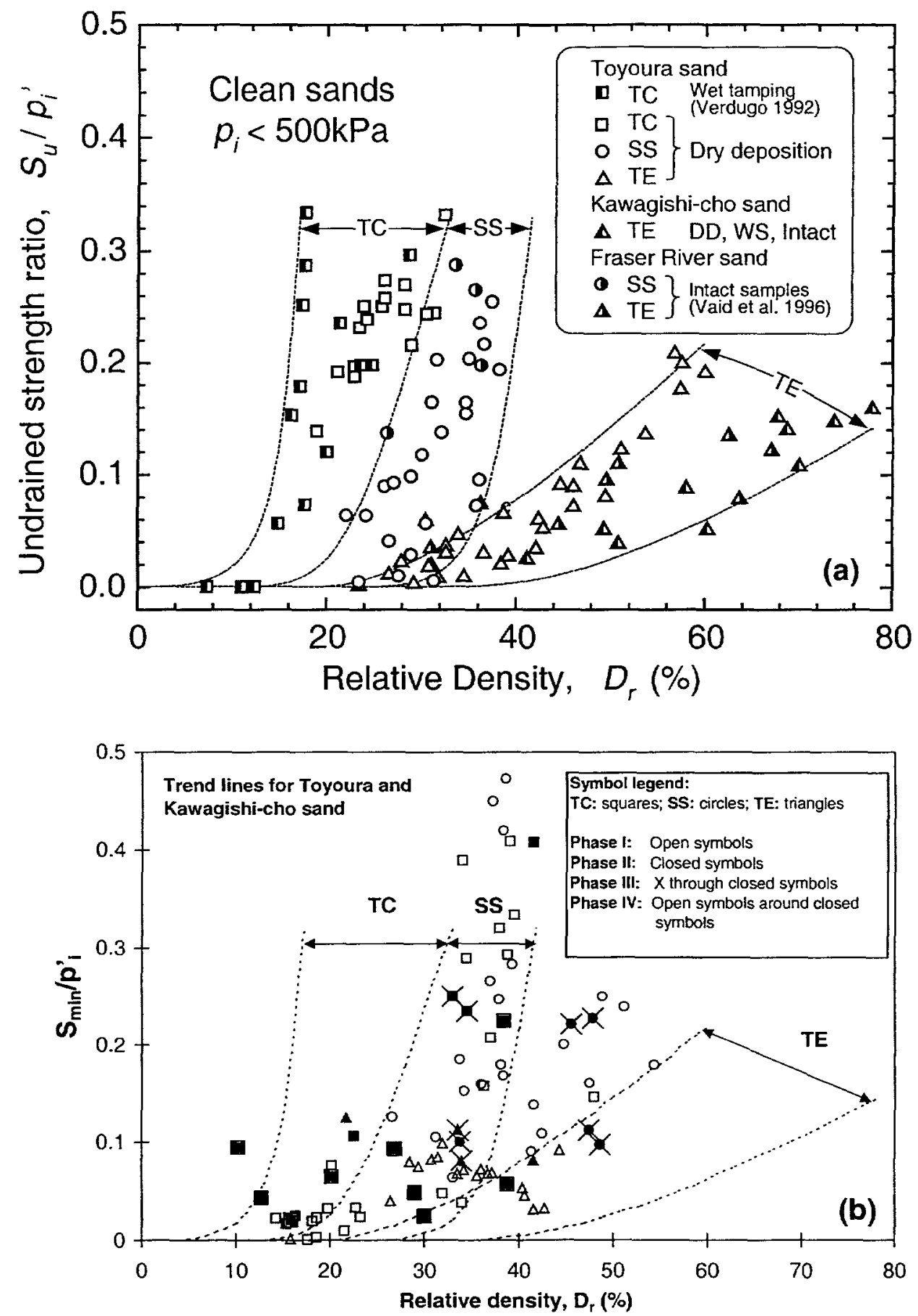

minimum undrained shear strength from $\left(N_{1}\right)_{60 \mathrm{cs}}$, although the data are too limited to provide recommendations at present. It is interesting to note that the data shown in Fig. 12 are minimum (quasi steady state) undrained shear strengths. End-of-test values of undrained strength plot significantly higher than the Seed and Harder range.

Figure $13 a$ shows the average and standard deviation of corrected SPT blow count, $\left(N_{1}\right)_{60}$, from the six CANLEX sites, along with the range of measured minimum undrained shear strength ratio from undisturbed samples $\left(S_{\min } / p_{i}^{\prime}\right)$ which demonstrated a strain-softening (type $B$ ) response. Also included in the plot is the relationship between $S_{\mathrm{u}} / \sigma_{\mathrm{i}}{ }^{\prime}$ and $\left(N_{1}\right)_{60}$ recommended by Stark and Mesri (1992) for clean sands. A $K_{0}$ of 0.5 was assumed to plot both $S_{\min } / p_{1}^{\prime}$ and $S_{\mathrm{u}} / \alpha_{i}^{\prime}$ in the same figure. Figure $13 b$ shows the average and standard deviation of equivalent clean sand corrected 
Fig. 8. Relationship between minimum undrained strength ratio and brittleness index for strain-softening samples (type A and B responses): (a) clean sand trend lines proposed by Yoshimine et al. (1999); (b) comparison of CANLEX reconstituted test results with trends observed by Yoshimine et al.
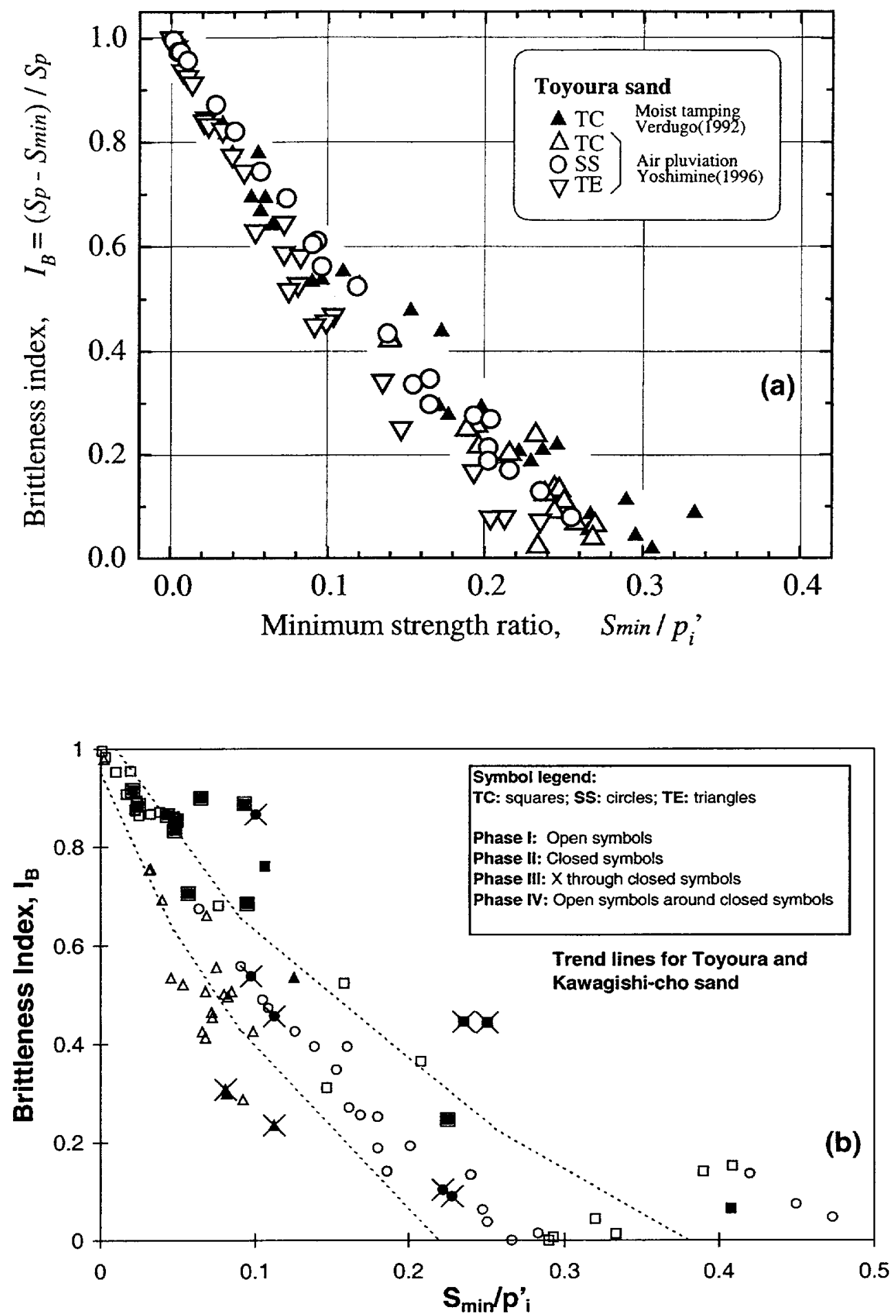

SPT blow count, $\left(N_{1}\right)_{60 \mathrm{cs}}$, from the six CANLEX sites. The average undrained shear strength value from the Duncan Dam in simple shear was around 0.21 over a range of $\left(N_{1}\right)_{60 \mathrm{cs}}$ from 8 to 14. Again, since not all of the CANLEX samples that were tested showed a strain-softening (type B) response, it is reasonable to take the average minus one standard deviation of SPT blow count as a more representa- tive measure of the associated in situ state. However, it may be more representative to take the average value of the SPT for the phase I and LL Dam (phase IV) sites, since those samples showed some densification during thaw and consolidation due to a lack of full saturation.

If the phase I results are assumed to be low due to the high stress level, the range suggested by Stark and Mesri 
Fig. 9. Relationship between state parameter and minimum undrained strength ratio for strain-softening samples (type A and B responses): (a) clean sand trend lines proposed by Yoshimine (1996); $(b)$ comparison of CANLEX reconstituted test results with trends observed by Yoshimine.
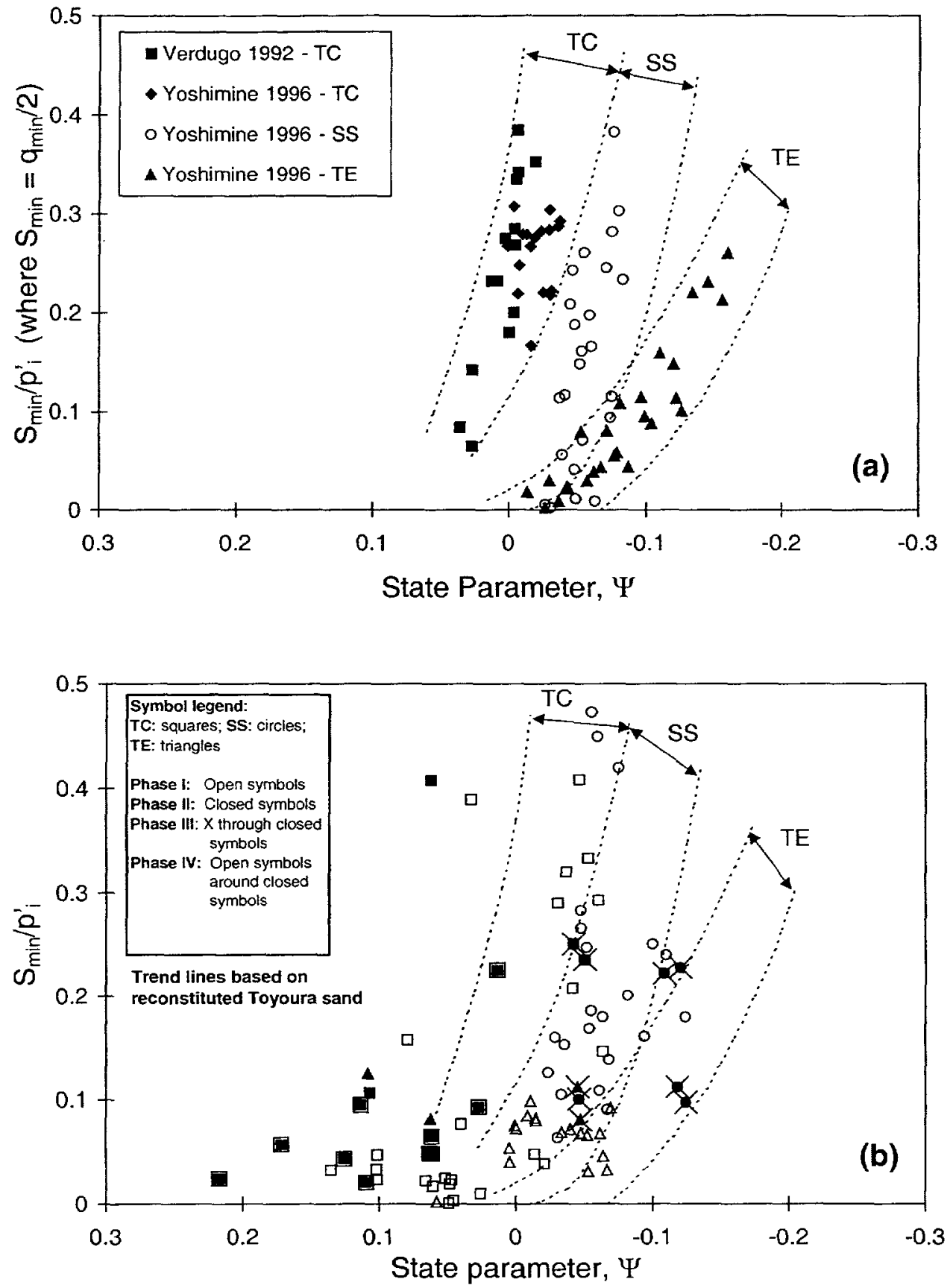

(1992) appears to fit closer to the triaxial extension and simple shear results, with the triaxial extension being closer to the suggested lower bound and the simple shear being closer to the suggested average and upper bound. Again, the suggested range significantly underpredicts the triaxial compression values. The end-of-test values of undrained shear strength ratio are significantly higher than the range suggested by Stark and Mesri.

Recently, Yoshimine et al. (1999) suggested that the normalized equivalent clean sand CPT penetration resistance, $\left(q_{\mathrm{clN}}\right)_{\mathrm{is}}$, can be used to estimate the minimum undrained strength ratio $\left(S_{\min } / \sigma_{v i}{ }^{\prime}\right)$ for clean sands. Yoshimine et al. suggested that the average minus one standard deviation of $\left(q_{\mathrm{c} 1 \mathrm{~N}}\right)_{\mathrm{cs}}$ may be a better representation of the in situ state for the evaluation of flow liquefaction, since instability will be driven by weaker zones. Figure $14 a$ shows the relationship between $S_{\mathrm{u}} / \sigma_{\mathrm{vi}}{ }^{\prime}$ and $\left(q_{\mathrm{c} I \mathrm{~N}}\right)_{\mathrm{cs}}$ suggested by Yoshimine et al. in terms of reconstituted Toyoura sand results and three flow liquefaction case histories for which the mean effective stress, $p_{i}^{\prime}$, was less than $500 \mathrm{kPa}$. Figure $14 b$ shows the average minus one standard deviation equivalent clean sand CPT $\left(q_{\mathrm{clN}}\right)_{\mathrm{cs}}$ values from the six CANLEX sites along with the 
Fig. 10. Undrained response of CANLEX ground-freezing samples which had a strain-softening (type B) response: (a) relationship between relative density $\left(D_{\mathrm{r}}\right)$ and minimum undrained strength ratio; $(b)$ relationship between minimum undrained strength ratio and brittleness index.
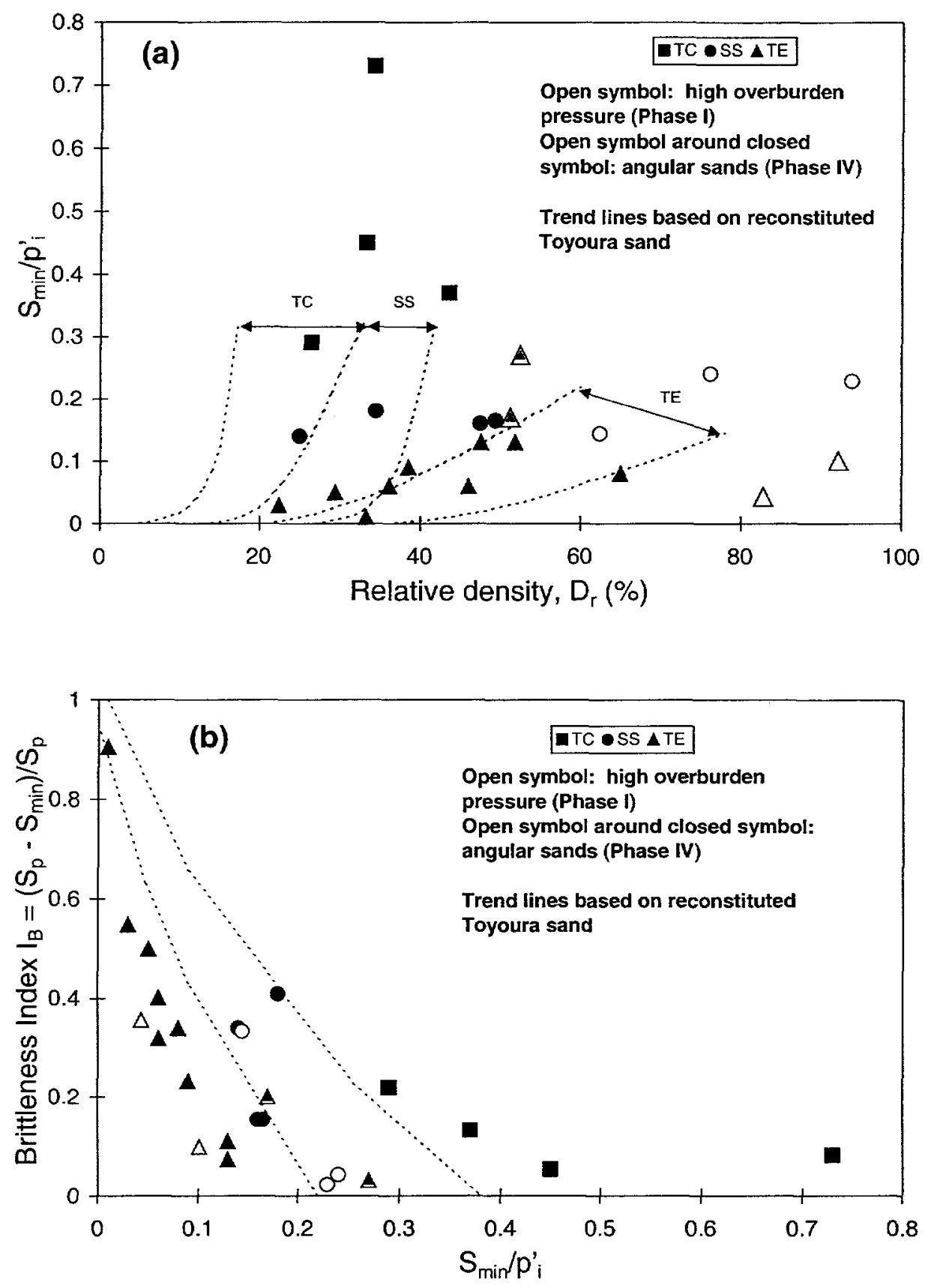

range of measured minimum undrained shear strength ratio from undisturbed samples $\left(S_{\min } / p_{\mathrm{i}}^{\prime}\right)$ which demonstrated a type $\mathrm{B}$ response. Also included in the plot is the relationship between $S_{\mathrm{u}} / \sigma_{\mathrm{vi}}^{\prime}$ and $\left(q_{\mathrm{c} 1 \mathrm{~N}}\right)_{\mathrm{cs}}$ suggested by Yoshimine et al., based on the SS direction of loading and the three case histories. A $K_{0}$ of 0.5 was assumed to plot both $S_{\min } / p_{i}^{\prime}$ and $S_{\mathrm{u}} / \sigma_{v i}^{\prime}$ in the same figure.

If the phase I results are assumed to be low due to the high stress level, the CANLEX test results agree quite well with the range suggested by Yoshimine et al. (1999). The phase IV results for angular sand again show a significantly higher undrained strength ratio at the same $\left(q_{\mathrm{clN}}\right)_{\mathrm{cs}}$. The sim- ple shear results from phase I are considerably lower than the range suggested by Yoshimine et al., indicating a possible large correction to account for high stress levels. Based on the shape of the USLs shown in Fig. 2, grain crushing and the influence of high stresses may be important at stresses $\left(p^{\prime}\right)$ greater than $200 \mathrm{kPa}$. Yoshimine et al. also suggested that the relationship for simple shear appears to agree well with case histories of flow liquefaction. The simple shear test results from the Massey and J-pit sites agree well with the relationship suggested by Yoshimine et al.

Figure 15 shows the average and standard deviation of normalized shear wave velocity from the six CANLEX sites 
Fig. 11. Undrained response of strain-softening CANLEX ground-freezing samples (type B response) in terms of state parameter ( $\Psi$ ).

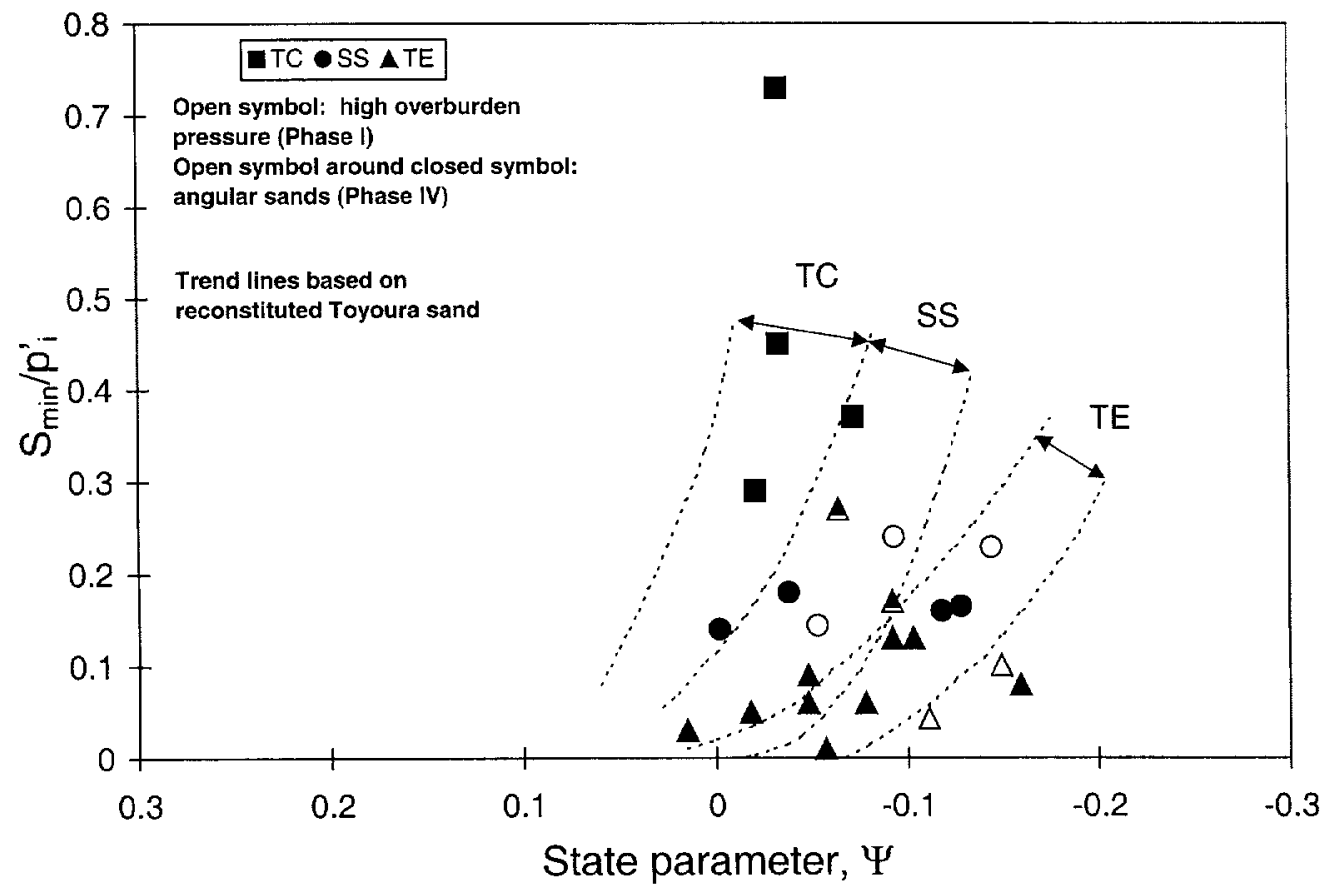

and the range of measured minimum undrained shear strength from undisturbed samples $\left(S_{\text {min }}\right)$ which demonstrated a type B response. Also included are the relationships between $S_{\mathrm{u}}$ and $V_{\mathrm{s} 1}$ for Fraser River sand $\left(K_{0}=0.5\right)$ at ultimate state for TC (based on Fear and Robertson 1995) and quasi steady state for TE (based on Robertson and Fear 1995). Fear and Robertson (1995) suggested that the normalized shear wave velocity was useful for identifying a possible strain-softening response, but, due to the sensitivity of the relationship, it was not recommended for estimating the value of the minimum undrained shear strength. The results from this study confirm this observation. A normalized shear wave velocity of around $160 \mathrm{~m} / \mathrm{s}$ appears to represent the critical value for a strain-softening (type B) response to undrained simple shear, although strain softening in triaxial extension loading was observed at larger values of normalized shear wave velocity.

Several techniques have been suggested for estimating the stress-strain response of sands from self-boring pressuremeter tests (Hughes et al. 1997; Roy et al. 1998). These methods are based on computer-aided modelling of the pressuremeter response curves. Computer-aided modelling can be based on either simple stress-strain relationships to estimate the likely state of the sand (Hughes et al. 1997) or on more complex constitutive stress--strain models that require a numerical analysis of the pressuremeter (Roy et al. 1998). The method suggested by Roy et al. (1998) provided a reasonable comparison with measured stress-strain curves from laboratory testing on undisturbed samples, although the comparison was difficult due to the large variation within each deposit. The method by Hughes et al. (1997) also provided reasonable estimates of in situ response, although the range of measured responses was also wide.

\section{Summary and conclusions}

The major objectives of the CANLEX project were to develop test sites to study sand characterization; develop and evaluate undisturbed sampling techniques; calibrate and evaluate in situ testing techniques; and obtain an improved understanding of the phenomenon of soil liquefaction. In general, all of the major objectives of the project have been achieved. The following provides a summary of all the major findings from the CANLEX project.

Six sites were selected in Western Canada to study sitecharacterization techniques for soil liquefaction. The sites were selected to provide a range of different loose sand deposits. The deposits varied in age from 2 months to over 4000 years. The sands were uniformly graded, with an average grain size $\left(D_{50}\right)$ of about $0.20 \mathrm{~mm}$ and fines content $(<74 \mu \mathrm{m})$ generally less than $15 \%$. The sands were composed primarily of quartz, with small amounts of feldspars and mica. The Fraser River sand had higher amounts of feldspars and mica. The sand grains ranged from subrounded to angular. All of the sands appear to be uncemented and essentially normally consolidated. At each site, a small target zone within the deposit was identified for detailed study. The target zones were generally only $4-5 \mathrm{~m}$ thick and $10 \mathrm{~m}$ in diameter in an effort to minimize the variability within the sands. The average effective overburden stress in the target zones ranged from 53 to $495 \mathrm{kPa}$. Two sites had natural sands which were deposited hydraulically as part of the oil-sands extraction process in Alberta. Two sites had natural sands as part of the extensive channel deposits of the Fraser River, near Vancouver, British Columbia. Two sites had hydraulically placed tailings sands resulting from the hard-rock mining operations of Highland Valley Copper, south of 
Fig. 12. Comparison of CANLEX data for ground-freezing samples which had a strain-softening (type B) response with Seed and Harder (1990) clean sand relationships: $(a)$ in terms of SPT $\left(N_{1}\right)_{60} ;(b)$ in terms of clean sand equivalent SPT $\left(N_{1}\right)_{6(k s .}$.
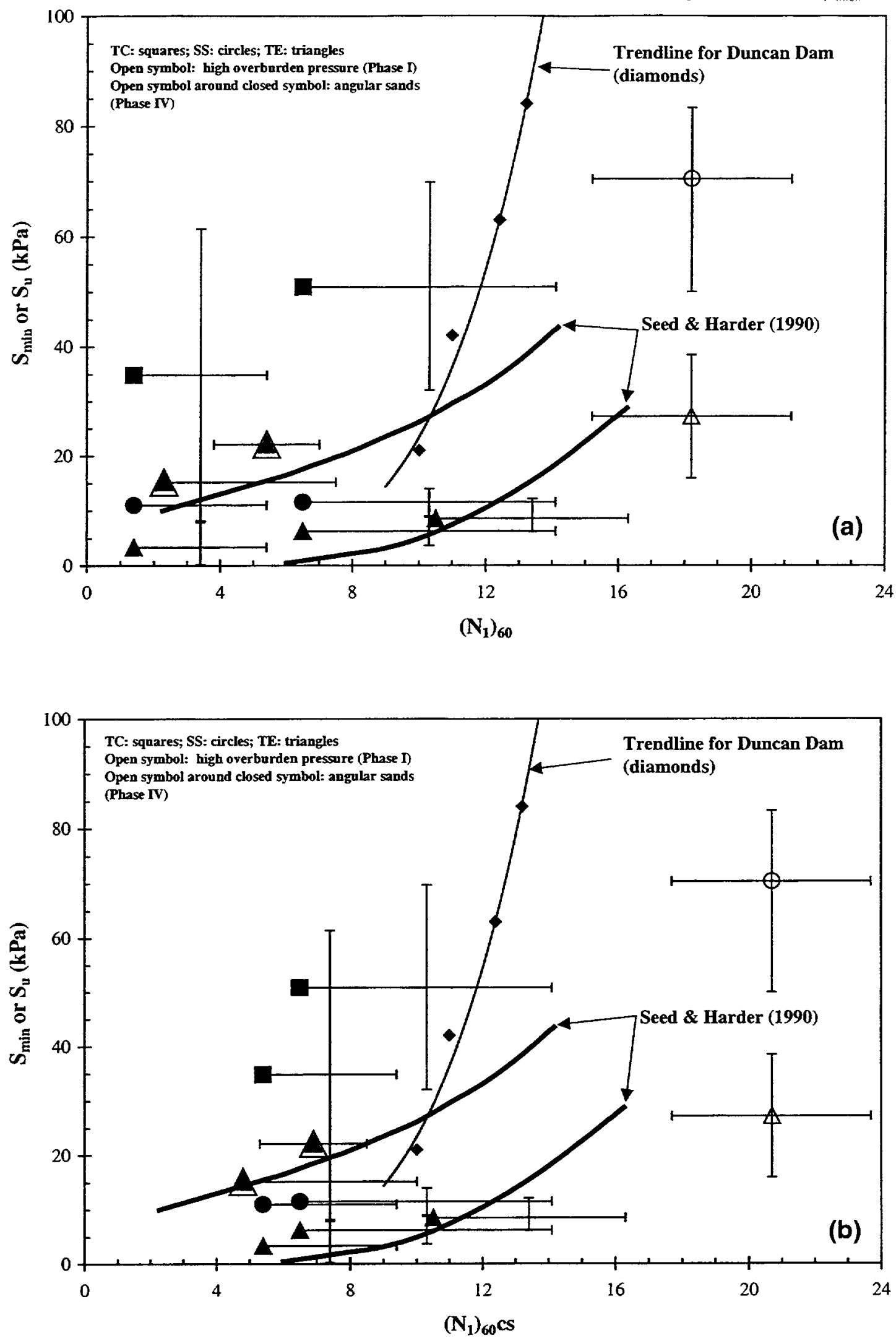
Fig. 13. Comparison of CANLEX data for ground-freezing samples which had a strain-softening (type B) response with Stark and Mesri (1992) clean sand relationships: $(a)$ in terms of SPT $\left(N_{1}\right)_{60} ;(b)$ in terms of clean sand equivalent SPT $\left(N_{1}\right)_{60 c s} . K_{0}=0.5$ has been used to show $S_{\text {min }} / p_{\mathrm{i}}^{\prime}$ and $S_{\mathrm{u}} / \sigma_{\mathrm{vi}}^{\prime}$ in the same plot.
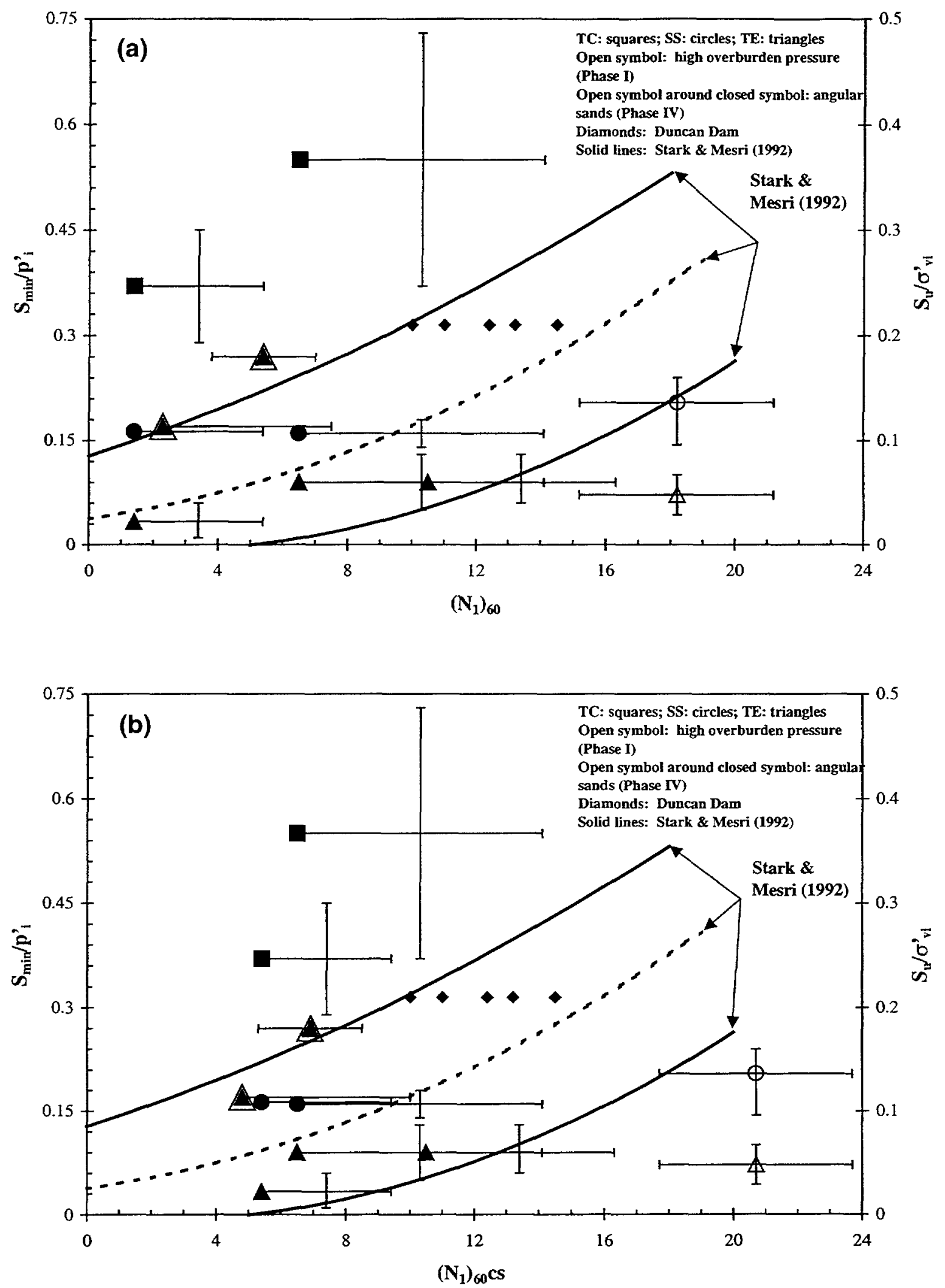
Fig. 14. Relationships between minimum undrained shear strength ratio and CPT: (a) after Yoshimine et al. (1999); (b) CANLEX ground-freezing samples having a strain-softening (type B) response data compared with the Yoshimine et al. relationship. $K_{0}=0.5$ has been used to show $S_{\min } / p_{\mathrm{i}}^{\prime}$ and $S_{\mathrm{u}} / \sigma_{\mathrm{vi}}{ }^{\prime}$ in the same plot.
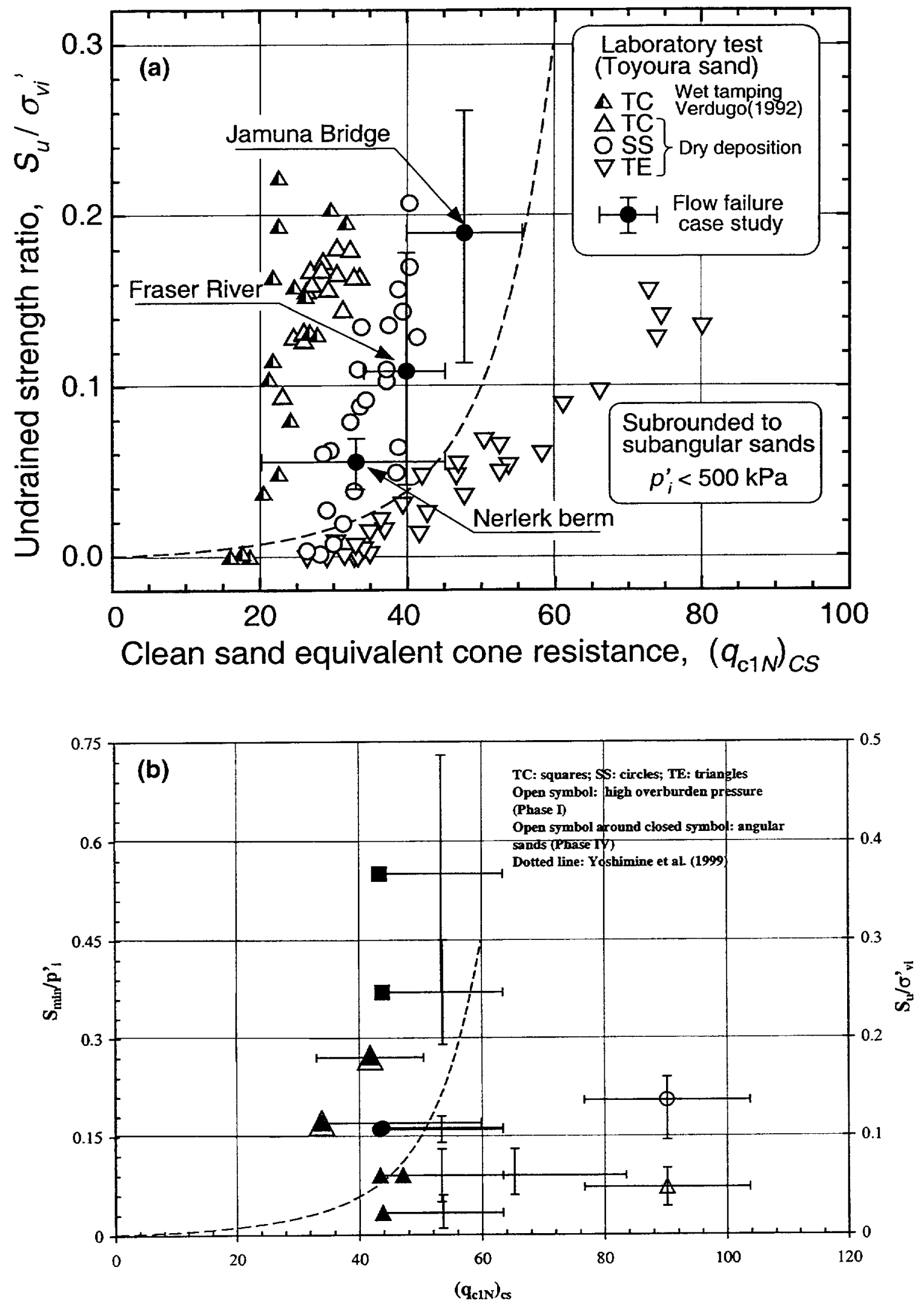
Fig. 15. Comparison of relationship between minimum undrained shear strength and shear wave velocity for CANLEX ground-freezing samples having a strain-softening (type B) response and relationships for Fraser River sand (after Fear and Robertson 1995; and Robertson and Fear 1995).

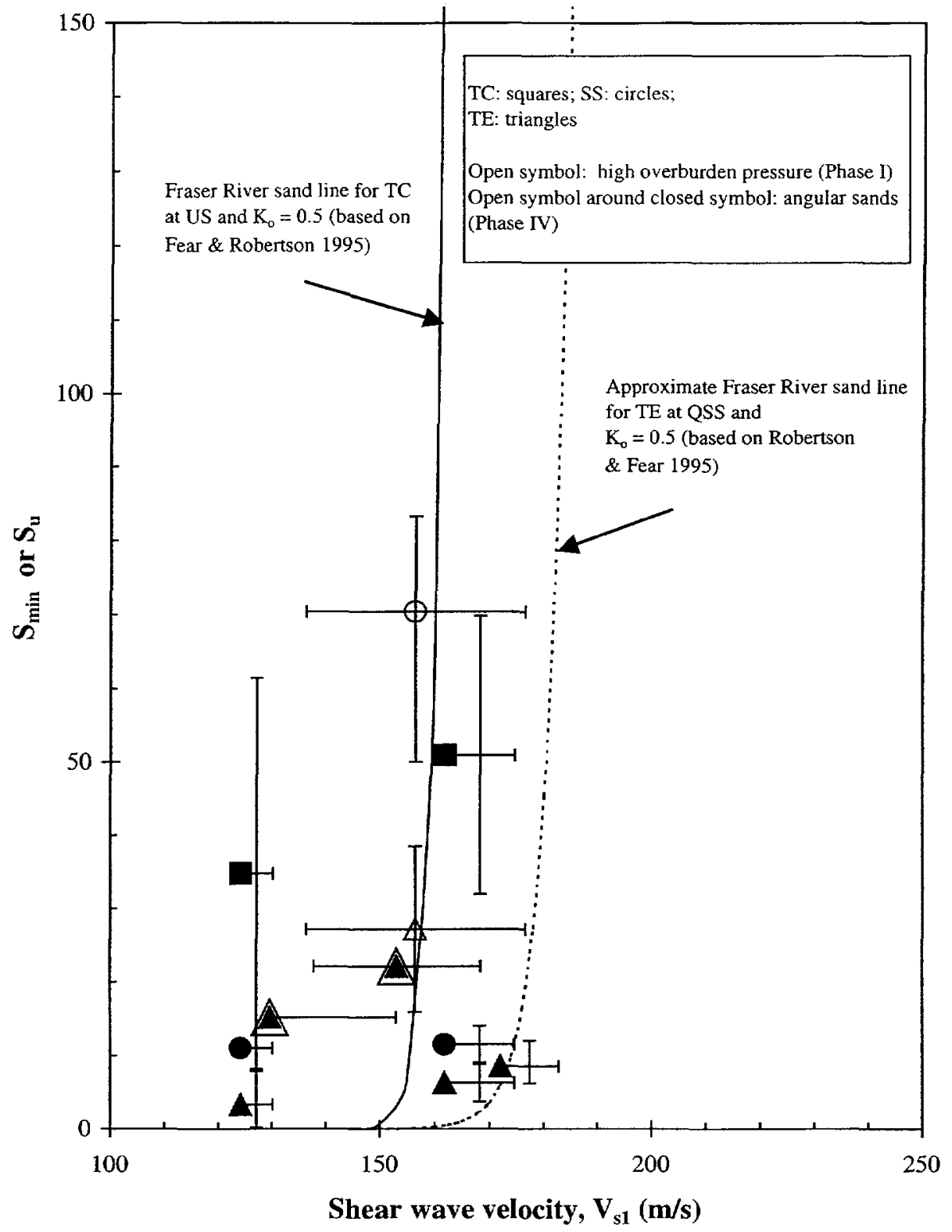

Kamloops, British Columbia. Not all deposits were saturated below the groundwater table. Two deposits (Mildred Lake and LL Dam) produced samples for which the degree of saturation was less than $100 \%$, possibly due to gas generation from residual bitumen and local depositional history.

A major observation from the project was the extreme variability of these sand deposits. Although small target zones were selected for detailed study, the deposits had high variability within these target zones. The variability was expressed by rapid changes in void ratio (relative density), both vertically and laterally, as well as small changes in grain characteristics, such as grain-size distribution and fines content. The rapid variations in void ratio observed with the undisturbed samples may be due, in part, to the small physical size of the samples, as compared with the void ratio vari- ations measured or inferred from the geophysical logging and the CPT. The variations in grain characteristics influenced the associated index parameters $\left(e_{\max }, e_{\min }\right.$, and specific gravity $G_{\mathrm{s}}$ ) and, to some degree, the soil fabric. Variations in grain characteristics were visible in the undisturbed samples. Hence, it was difficult to select representative average values for some index parameters, especially when the fines content was higher. The rapid variations in void ratio made it difficult to generalize the response of the sand to loading and to make simple comparisons between laboratory results and in situ test results.

The rapid and wide variations in void ratio and in situ test results illustrate the difficulty of identifying representative values for a given deposit to evaluate liquefaction susceptibility (either cyclic or flow liquefaction). Since not all of the 
samples tested showed a strain-softening response to undrained shear, it is likely that the representative values for a given deposit should not be average values, but more likely the 20 th percentile values (i.e., $20 \%$ of values are smaller). Further research is required to clarify this important issue.

A major objective of the project was to obtain undisturbed samples of the sand deposits. Modifications to the groundfreezing technique were developed and evaluated to obtain high-quality undisturbed samples from discrete target zones. Factors that influence ground freezing and sampling in sandy soils were evaluated and quantified (Hofmann et al. 2000). Factors affecting high-quality fixed piston sampling in sandy soils were also evaluated and quantified (Plewes and Hofmann 1995). High-quality samples were obtained using fixed piston sampling techniques at three of the CANLEX sites. However, despite careful sampling and subsequent freezing (for preservation), the fixed piston samples obtained from two of the saturated sites were, on average, somewhat denser (change in void ratio, $\Delta e=-0.03$ to -0.05 ) than the samples obtained using ground freezing. This agrees with similar data obtained at Duncan Dam (Plewes et al. 1994). Fixed piston sampling at one of the unsaturated sites (Mildred Lake) resulted in larger density changes $(\Delta e=$ -0.10 to -0.15$)$. Hence, the use of conventional sampling techniques to determine the in situ density of loose, unsaturated sands should be avoided. Sampling using double-tube coring techniques proved to be useful for obtaining core for soil identification purposes only (Plewes 1993). Rotaryvibration (sonic) cores also proved to be useful for stratigraphic logging, although some detail can be lost due to liquefaction of the loose sediments during vibrations. The Laval large-diameter piston sampler was also evaluated at three sites, with success at only one site and limited success at another. Adequate mud flow during overcoring was identified as a key factor in successful sampling using the largediameter piston sampler. In addition, the large-diameter piston sampler may not be suitable in deposits that contain any gravel-sized particles.

Improvements were made to sample handling procedures to ensure sample quality during sampling, transportation, and storage. Samples (other than those from ground freezing) were frozen on site prior to transportation and storage. Samples were stored in freezers between layers of insulation and ice and maintained at $-20^{\circ} \mathrm{C}$. Full details are given in a companion paper (Wride et al. $2000 \mathrm{a}$ ).

The in situ test results, in particular the CPT and geophysical (gamma-gamma) logging, confirmed the rapid variations of in situ density, although the variation was more subdued than that observed from samples. The existing empirical correlations to estimate relative density from the SPT, CPT, and shear wave velocity generally provided reasonable agreement with the undisturbed samples, although the age of the deposit had a significant influence, especially for deposits older than about 100 years. The geophysical logging provided good agreement with the undisturbed samples except at one site (Kidd) where the logging was unable to meet acceptable criteria for borehole rugosity. High-quality (gamma-gamma) borehole geophysical logging requires an uncased, mud-filled borehole with a uniform, smooth borehole wall. The borehole geophysical logging slightly overpredicted the void ratio of the ground-freezing samples at the two sites at which the in situ degree of saturation was less than $100 \%$ in the target zones. Gamma-gamma logging was also carried out using a new radioisotope CPT (Mimura et al. 1995) at the two phase II sites. Results were very good and the radioisotope CPT shows promise. The CPT-based method by Plewes et al. (1992) provided good predictions of in situ state parameter $(\Psi)$ compared with those of the undisturbed samples, with a slight tendency to predict denser states for the older deposits.

The self-boring pressuremeter provided reasonable results in terms of in situ horizontal stresses and estimates of in situ state and stress-strain characteristics. The pressuremeter results indicated a range of in situ $K_{0}$ values at each site, and an average value of 0.5 was selected. Interpretation of pressuremeter results to estimate stress-strain characteristics based on computer-aided modelling of the pressuremeter response curves (Roy et al. 1998) provided a reasonable comparison with measured stress-strain curves from laboratory testing on undisturbed samples, although the comparison was difficult due to the large variation within each deposit. The pressuremeter-CPT-based method to estimate in situ state parameter by Yu et al. (1996) underpredicted the state (i.e., predicted denser states) compared with those of the undisturbed samples.

A total of 121 undisturbed samples were tested in straincontrolled monotonic loading and a total of 37 undisturbed samples were tested in cyclic loading from the six sites. The large variability in void ratio has made it difficult to generalize the expected in situ response to loading, since it was not possible to test undisturbed samples over their full range of in situ states. Two main methods for thawing and consolidating frozen undisturbed samples were evaluated. One involved thaw and consolidation at the in situ stresses and the other involved thaw at a low stress followed by reconsolidation to the in situ stresses. Although no consensus was reached on the recommended thaw-consolidation protocol, it was agreed that great care is required to ensure minimal changes in void ratio during thaw and consolidation. Lack of saturation had a significant influence on the changes in void ratio during thaw and consolidation. When samples were fully saturated in situ, both thaw-consolidation methods provided good results with generally very small changes in void ratio $(\Delta e<0.02)$. Freezing helps maintain the in situ stress state in samples; however, ice will creep under high shear stresses. Hence, storing frozen samples for an excessive time before testing is not recommended and samples should be stored at around $-20^{\circ} \mathrm{C}$ to minimize creep. Creep of the pore ice will likely have a greater influence on changes in stress state for samples with high in situ stresses (i.e., $>300 \mathrm{kPa}$ ) and high values of stress anisotropy (i.e., $K_{0}<1.0$ ).

A major observation from the laboratory testing was that the undrained stress-strain response of undisturbed samples was strongly influenced by the direction of loading, with triaxial compression (TC) being considerably stronger than triaxial extension (TE). Simple shear response was generally intermediate between compression and extension response. This result is consistent with previous observations for clay soils (Bjerrum 1972) and recent observations for reconstituted sands (Hanzawa 1980; Georgiannou et al. 1990; Yoshimine 1996; Vaid and Sivathayalan 1996). 
Jamiolkowski et al. (1985) showed that the difference in undrained shear strength due to direction of loading in clay soils was a function of soil plasticity, with the difference becoming larger with decreasing soil plasticity. The results from this study confirm that observation, since the sands that were tested were nonplastic and the difference in undrained shear strength was large. The variation in minimum undrained shear strength in sand due to direction of loading is also a function of sand state or relative density. The difference in minimum undrained strength became less as the sand became looser. The monotonic undrained response of the sands was also influenced by the anisotropic consolidation stress state. Samples were more brittle in TC and less brittle in TE when the initial stress state was anisotropic $\left(K_{0}=0.5\right)$, compared with isotropically consolidated samples $\left(K_{0}=1.0\right)$.

Although the selected test sites were expected to have loose sand deposits based on past in situ testing criteria, an undrained strain-softening response was observed in only $8 \%$ of the samples tested in triaxial compression, $30 \%$ of those tested in simple shear, and $40 \%$ of the those tested in triaxial extension. In general, it was the looser undisturbed samples that showed a strain-softening response in triaxial extension at all sites, although this trend was not always clear. In simple shear, strain softening was observed at only three sites (Mildred Lake, Massey, and J-Pit), and in triaxial compression it was observed at only two sites (Massey and J-Pit). All samples showed some strain hardening at large strains, even in triaxial extension loading. The degree of brittleness and amount of strain occurring during minimum strength was larger for samples with a lower minimum undrained strength ratio, for a given direction of loading. Strain softening of samples from the Kidd site was observed only in triaxial extension, even though this site had some of the loosest in situ states. This was due, in part, to the limited testing program being unable to select and test the loosest samples and the possible influence of the age of these sands ( $>4000$ years).

Test results on reconstituted samples generally showed reasonable agreement with the results on undisturbed samples obtained using ground freezing. The results confirmed that the sands were uncemented. Reconstituted samples prepared using water-pluviation techniques generally showed better agreement with the undisturbed samples for Syncrude sand. However, the in situ void ratio of a significant portion of the target zones at several sites had void ratios looser than could be obtained using water-pluviation techniques in the laboratory. Reconstituted samples made using air-pluviation and moist-tamping techniques were generally weaker than similar samples made using water-pluviation techniques for Syncrude sand. A detailed comparison of different modes of deposition was not made for Fraser River or HVC sands. The in situ testing results showed the importance of aging, with the older sites (Massey and Kidd) showing a significant increase in penetration resistance and shear wave velocity due to age. Hence, it may be possible to predict the in situ response of clean sands based on testing reconstituted samples made to their in situ void ratio and stress levels, provided that the sands are uncemented and their ages do not exceed about 100 years. Further research is required to clarify the influence of age, fines content (and other grain characteristics), and method of sample preparation on the monotonic undrained stress-strain response of sands. It is likely that sample preparation for reconstituted testing becomes more important as the fines content and grain angularity increase.

Based on the results of the monotonic laboratory testing on both undisturbed and reconstituted samples, it was difficult to determine a unique steady (ultimate) state line for the sands at the CANLEX sites. This was partly due to the significant differences in undrained response due to differences in direction of loading and the limited strain range available with most laboratory equipment. However, since techniques have been developed based on steady state concepts (e.g., Konrad and Watts 1995), reference ultimate state lines (USLs) were estimated for each sand based primarily on triaxial compression test results. Konrad and Pouliot (1997) present some of the results for phase II of the CANLEX project. These USLs were used to estimate the in situ state parameters so that the measured laboratory response could be compared at different states. For all of the sites, the observed undrained monotonic response for undisturbed samples related to state parameter slightly better than to relative density, although wide scatter was observed for both approaches. The observed scatter was slightly larger for reconstituted CANLEX sand samples, which may reflect the sensitivity of the measured response to the small variations in grain characteristics within these sand deposits. The observed undrained monotonic response was dominated by the direction of loading. In general, the average overall state of these deposits was slightly dense of the reference USL, with a small percentage being loose of the reference USL.

The laboratory undrained cyclic test results on undisturbed samples compared well with the SPT, CPT, and shear wave velocity cyclic resistance ratio (CRR) curves recommended by the 1996 NCEER Workshop (Youd and Idriss 1997). These results are consistent with previous studies based on undisturbed frozen samples (Yoshimi et al. 1994; Pillai and Stewart 1994). The correction factor $\left(K_{\sigma}\right)$ for high overburden stress worked well for the SPT-based method, but less so for the CPT and shear wave velocity methods. At the sites for which samples were not fully saturated (Mildred Lake and LL Dam), the measured CRR was slightly larger than predicted based on the NCEER recommended curves. This is consistent with recent research on gassey sands (Grozic 1999).

The laboratory monotonic test results of minimum (quasi steady state) undrained shear strength from undisturbed samples that were strain softening (type B response), for the sands with subrounded grains and at sites at which the effective overburden stress was not high $\left(\sigma_{v}^{\prime} \approx 100 \mathrm{kPa}\right)$, compare reasonably well with the empirical correlations proposed by Seed and Harder (1990) and Stark and Mesri (1992) based on case histories and the SPT. In general, the triaxial extension results are closer to the suggested lower bounds and the simple shear results are closer to the upper bounds. The triaxial compression results are significantly higher than the suggested ranges. The measured minimum undrained shear strength values also compare well with the correlations based on the CPT and shear wave velocity by Yoshimine et al. (1999) and Fear and Robertson (1995), respectively. The results from this study indicate that the minimum undrained shear strengths of angular sands are 
noticeably higher than for those for rounded sands. The minimum undrained shear strengths at the one site for which the effective overburden stress was high $\left(\sigma_{\mathrm{vi}}^{\prime} \approx 500 \mathrm{kPa}\right)$ were generally lower than would be predicted using the existing empirical correlations based on in situ tests. The end-of-test values (typically at $15-20 \%$ strain) of undrained shear strength were significantly higher than the values predicted based on in situ tests. This may be due to the fact that the samples were tested under strain-controlled conditions (Hanzawa 1980).

It is interesting to note that the average cyclic resistance ratio for 15 cycles in cyclic simple shear $\left(\mathrm{CRR}_{\mathrm{ss}}=\tau_{\mathrm{cyc}} / \sigma_{\mathrm{vi}}{ }^{\prime}\right)$ for all of the sites at which the in situ effective overburden stress is close to $1 \mathrm{~atm}$ ( $1 \mathrm{~atm}=101.325 \mathrm{kPa}$ ) was around 0.10 . It is also interesting to note that the average minimum undrained strength ratio $\left(S_{\min } / \sigma_{\mathrm{vi}}{ }^{\prime}\right)$ for simple shear loading for the same sites was also around 0.10 . However, the monotonic resistance appears to be much more sensitive to small changes in void ratio and grain characteristics than the cyclic resistance. The NCEER-recommended correction factor (Youd and Idriss 1997) to correct the predicted CRR for high effective overburden stress at the Mildred Lake site $\left(K_{\sigma}=\right.$ 0.76 at $\sigma_{\mathrm{vi}}^{\prime}$ of $330 \mathrm{kPa}$ ) was consistent with the test results on undisturbed samples tested at their in situ stress and the SPT. Based on the limited test results from this study, it would appear that a similar correction factor for high overburden stress may apply to the minimum undrained shear strengths predicted using the existing empirical correlations.

As part of the CANLEX project, a study was carried out to evaluate analysis procedures for predicting the flow liquefaction phenomenon. Two experimental test types were carried out, a full-scale field test comprised of an embankment built over a loose saturated sand deposit, and centrifuge tests performed on models of the prototype field test. Both test types were designed to induce flow liquefaction under monotonic (static) loading. Two different stress-strain models were used in numerical analyses to predict and match the tests. The results from both stress-strain model approaches were found to be in reasonable agreement with the measurements, provided that allowance was made for direction of loading and drainage. The analyses showed that the traditional approach of using limit equilibrium techniques and minimum (residual) undrained shear strengths based on existing empirical correlations from the SPT may be unduly conservative, since the undrained strength in the zone where compression loading is acting may be much higher than assumed and drainage leading to increased strength may be significant. The results of the full-scale field test and analyses indicate that steep slopes can be constructed over loose saturated sands, provided that the rate of loading is such that drainage and consolidation can occur. If undrained loading is subsequently triggered, due to possible shock loading or a rising groundwater level, the response will be strongly influenced by the geometry and resulting direction of loading. Full details of the modelling and tests are given in a companion paper by Byrne et al. (2000).

The appropriate site characterization for the evaluation of liquefaction potential should depend on the level of risk associated with the project (Robertson 1998). For low-risk projects or for the initial screening of high-risk projects, the existing empirical correlations based on in situ tests (SPT,
CPT, or $V_{\mathrm{s}}$ ) are likely appropriate and conservative for both cyclic and flow liquefaction. However, it is important that direction of loading be taken into account for flow liquefaction. The CPT has the advantage of producing continuous profiles of data. The results of this study can be used to improve the estimates of undrained shear strength as a function of direction of loading, high in situ stresses, and grain angularity. For low-risk projects, it is generally appropriate to retain some level of conservatism in the empirical correlations. For moderate-risk projects, it may be appropriate to add geophysical (gamma-gamma) logging to aid in the estimate of in situ density, as well as selected laboratory testing. Laboratory testing may be appropriate on undisturbed samples of fine-grained soils (silty clays, clayey silts) for which the existing empirical techniques often require large corrections and undisturbed samples may be obtained using conventional techniques. Laboratory testing on reconstituted samples made to their in situ void ratios and stress levels may also be appropriate if the sands are clean (fines content $<5 \%$ ), uncemented, and unaged (age $<100$ years). For highrisk projects, for which the consequences of liquefaction can be severe and the cost of undue conservatism very high, consideration should be given to obtaining undisturbed samples using ground freezing in potentially critical zones, as identified by using existing empirical techniques based on in situ testing. Hence, for high-risk projects, consideration should be given to carrying out a site-characterization program similar to that carried out at these CANLEX sites. A recent example where this was done successfully is the detailed investigation at the Duncan Dam as part of a dam safety review by B.C. Hydro (Little et al. 1994).

\section{Acknowledgments}

This work was supported by CANLEX (Canadian Liquefaction Experiment), which is a project funded through a Collaborative Research and Development Grant from the Natural Sciences and Engineering Research Council of Canada (NSERC), B.C. Hydro, Highland Valley Copper, Hydro Quebec, Kennecott Corporation, Suncor Inc., and Syncrude Canada Ltd. The collaboration included the geotechnical consultants, AGRA Earth and Environmental Ltd., EBA Engineering Consultants Ltd., Golder Associates Ltd., KlohnCrippen Consultants Ltd., and Thurber Engineering Ltd., as well as faculty and students from the University of Alberta, The University of British Columbia, Carleton University, and Universite Laval. The CANLEX project also appreciated the participation of the following organizations: the Geological Survey of Canada (GSC), B.C. Ministry of Transportation and Highways (BC MOTH), B.C. Ministry of Energy and Mines, the Centre for Cold Ocean Resources Engineering (C-CORE), ConeTec Investigations Ltd., and Hughes InSitu Engineering Inc. A project of this size cannot be carried out without the hard work of many people. The dedication of the main participants from industry, engineering consultants, university researchers, support staff, technicians, and graduate students is very much appreciated. In particular, Dr. Y.P. Vaid of The University of British Columbia played a major role in the laboratory testing aspects of the project. The financial support, both cash and in kind, from the participants and NSERC is also appreciated. 


\section{References}

Andrus, R.D. 1994. In situ characterization of gravelly soils that liquefied in the 1983 Borah Peak earthquake. Ph.D. thesis, University of Texas at Austin, Austin, Tex.

Andrus, R.D., and Stokoe, K.H. 1998. Guidelines for evaluation of liquefaction resistance using shear wave velocity. In Proceedings of the National Center for Earthquake Engineering Research (NCEER) Workshop on Evaluation of Liquefaction Resistance of Soils, Salt Lake City, Utah, January 1996. Edited by T.L. Youd and I.M. Idriss. National Center for Earthquake Engineering Research, Report NCEER-97-0022, pp. 89-128.

Been, K., and Jefferies, M.G. 1985. A state parameter for sands. Géotechnique, 35(2): 99-112.

Been, K., and Jefferies, M.G. 1992. Towards systematic CPT interpretation. In Proceedings of the Wroth Symposium, Oxford, U.K. pp. 44-55.

Been, K., Crooks, J.H.A., Becker, D.E., and Jefferies, M.G. 1986. The cone penetration test in sands: part I. State parameter interpretation. Géotechnique, 36(2): 239-249.

Been, K., Jefferies, M.B., Crooks, J.H.A., and Rothenburg, L. 1987. The cone penetration test in sands, part 2. General inference of state. Géotechnique, 37(3): 285-299.

Bishop, A.W. 1967. Progressive failure - with special reference to the mechanism causing it. Panel discussion. In Proceedings of the Geotechnical Conference, Oslo, Norway, Vol. 2, pp. 142150.

Bjerrum, L. 1972. Embankments on soft ground. In Proceedings of the American Society of Civil Engineers (ASCE) Specialty Conference on Performance of Earth and Earth Supported Structures, Purdue University, Lafayette, Ind., Vol. 2, pp. 1-54.

Byrne, P.M., Puebla, H., Chan, D.H., Soroush, A., Morgenstern, N.R., Cathro, D.C., Gu, W.H., Phillips, R., Robertson, P.K., Hofmann, B.A., Wride (Fear), C.E., Sego, D.C., Plewes, H.D., List, B.R., and Tan, S. 2000. CANLEX full-scale experiment and modelling. Canadian Geotechnical Journal, 37: 543-562.

Fear, C.E., and McRoberts, E.C. 1995. Reconsideration of initiation of liquefaction in sandy soils. Journal of Geotechnical Engineering, ASCE, 121(3): 249-261

Fear, C.E., and Robertson, P.K. 1995. Estimating the undrained strength of sand: a theoretical framework. Canadian Geotechnical Journal, 32: 859-870.

Georgiannou, V.N., Burland, J.B., and Hight, D.W. 1990. The undrained behaviour of clayey sands in triaxial compression and extension. Géotechnique, 40(3): 431-449.

Grozic, J. 1999. The behavior of loose gassy sand and its susceptibility to liquefaction. Ph.D. thesis, Department of Civil and Environmental Engineering, University of Alberta, Edmonton.

Hanzawa, H. 1980. Undrained strength and stability analysis for a quick sand. Soils and Foundations, 20(2): 17-29.

Hofmann, B.A., Sego, D.C., and Robertson, P.K. 2000. In-situ ground freezing to obtain undisturbed samples of loose sand for liquefaction assessment. Journal of Geotechnical and Geoenvironmental Engineering, ASCE. In press.

Hughes, J.M.O., Campanella, R.G., and Roy, D. 1997. A simple understanding of the liquefaction potential of sands from selfboring pressuremeter tests. In Proceedings of the 14th International Conference on Soil Mechanics and Foundation Engineering, Hamburg, Germany, Vol. 1, pp. 515-518.

Ishihara, K. 1993. Liquefaction and flow failure during earthquakes. The 33rd Rankine Lecture. Géotechnique, 43(3): 351415.

Jamiolkowski, M., Ladd, C.C., Germaine, J.T., and Lancellotta, R. 1985. New developments in field and laboratory testing of soils.
State-of-the-art report. In Proceedings of the 11 th International Conference on Soil Mechanics and Foundation Engineering, San Francisco. A.A. Balkema, Rotterdam, The Netherlands, Vol. 1, pp. 57-153.

Kayen, R.E., Mitchell, J.K., Lodge, A., Seed, R.B., Nishio, S., and Coutinho, R. 1992. Evaluation of SPT-, CPT-, and shear wavebased methods for liquefaction potential assessment using Loma Prieta data. In Proceedings of the 4th Japan - U.S. Workshop on Earthquake Resistant Design of Lifeline Facilities and Countermeasures for Soil Liquefaction. Edited by M. Hamada and T.D. O'Rourke. National Center for Earthquake Engineering Research (NCEER), Technical Report NCEER-94-0019. Vol. 1, pp. 177-204.

Kokusho, T., Yoshida, Y., and Eashi, Y. 1983. Evaluation of seismic stability of dense sand layer (Part 2) - evaluation method by standard penetration test. Electric Power Central Research Institute, Japan, Report 383026. (In Japanese.)

Konrad, J.-M., and Pouliot, N. 1997. Ultimate state of reconstituted and intact samples of deltaic sand. Canadian Geotechnical Journal, 34: 737-748.

Konrad, J.-M., and Watts, B.D. 1995. Undrained shear strength for liquefaction flow failure analysis. Canadian Geotechnical Journal, 32: 783-794.

Konrad, J.-M., Watts, B.D., and Stewart, R.A. 1997. Assigning the ultimate strength of foundation sand at Duncan Dam. In Proceedings of the 14th International Conference on Soil Mechanics and Foundation Engineering, Hamburg, Germany, Vol. 1, pp. 143-146.

Little, T.E., Imrie, A.S., and Psutka, J.F. 1994. Geologic and seismic setting pertinent to dam safety review of Duncan Dam. Canadian Geotechnical Journal, 31: 919-926.

Lodge, A.L. 1994. Shear wave velocity measurements for subsurface characterization. Ph.D. thesis, University of California at Berkeley, Berkeley, Calif.

Mimura, M., Shrivastava, A.K., Shibata, T., and Nobuyama, M. 1995. Performance of RI-cone penetrometers in sand deposits. In CPT'95, Proceedings of the International Symposium on Cone Penetration Testing, Linkoping, Sweden, Vol. 2, pp. 55 60 .

Mitchell, J.K., and Tseng, D.-J. 1990. Assessment of liquefaction potential by cone penetration resistance. In Proceedings of the H. Bolton Seed Memorial Symposium, Berkeley, Calif. Edited by J.M. Duncan. Vol. 2, pp. 335-350.

Olsen, R.S. 1988. Using the CPT for dynamic response characterization. In Proceedings of the Earthquake Engineering and Soil Dynamics Il Conference, American Society of Civil Engineers. St. Louis, U.S.A.

Olsen, R.S., and Koester, J.P. 1995. Prediction of liquefaction resistance using the CPT. In CPT'95, Proceedings of the International Symposium on Cone Penetration Testing, Linkoping, Sweden, Vol. 2, pp. 251-256.

Olsen, R.S., and Malone, P.G. 1988. Soil classification and site characterization using the cone penetrometer test. In Penetration Testing 1988, ISOPT-1. Edited by J. De Ruiter. A.A. Balkema, Rotterdam, The Netherlands, Vol. 2, pp. 887-893.

Pillai, V.S., and Stewart, R.A. 1994. Evaluation of liquefaction potential of foundation soils at Duncan Dam. Canadian Geotechnical Joumal, 31: 951-966.

Plewes, H.D. 1993. Conventional sampling summary report. CANLEX Technical Report, Phase I, Activity 4A, KlohnCrippen Consultants Ltd., Internal CANLEX Report.

Plewes, H.D., and Hofmann, B.A. 1995. Preservation and quality evaluation of sand samples obtained for the CANLEX project using thin-walled Shelby tubes. In Proceedings of the 48th 
Canadian Geotechnical Conference, Vancouver. BiTech Publishers Ltd. Richmond, B.C.

Plewes, H.D., Davies, M.P., and Jefferies, M.G. 1992. CPT based screening procedure for evaluating liquefaction susceptibility. In Proceedings of the 45th Canadian Geotechnical Conference, Toronto, Ont., pp. 4:1-4:9.

Plewes, H.D., Pillai, V.S., Morgan, M.R., and Kilpatrick, B.L. 1994. In situ sampling, density measurements, and testing of foundation soils at Duncan Dam. Canadian Geotechnical Journal, 31: 927-938.

Poorooshasb, H.B., and Consoli, N.C. 1991. The ultimate state. In Proceedings of the 9th Pan-American Conference, pp. 10831090 .

Robertson, P.K. 1994. Suggested terminology for liquefaction. In Proceedings of the 47th Canadian Geotechnical Conference, Halifax, N.S., pp. 277-286.

Robertson, P.K. 1998. Risk based site investigation. Geotechnical News, 16(3): 45-47.

Robertson, P.K., and Campanella, R.G. 1985. Liquefaction potential of sands using the cone penetration test. Journal of Geotechnical Engineering, ASCE, 111(GT3): 384-403.

Robertson, P.K., and Fear, C.E. 1995. Liquefaction of sands and its evaluation. In IS-Tokyo '95, Proceedings of the 1st International Conference on Earthquake Geotechnical Engineering, Tokyo. Edited by K. Ishihara. A.A. Balkema, Rotterdam, The Netherlands, Vol. 3, pp. 1253-1289.

Robertson, P.K., and Wride (Fear), C.E. 1998a. Evaluating cyclic liquefaction potential using the cone penetration test. Canadian Geotechnical Journal, 35: 442-459.

Robertson, P.K., and Wride (Fear), C.E. 1998b. Cyclic liquefaction and its evaluation based on the SPT and CPT. In Proceedings of the National Center for Earthquake Engineering Research (NCEER) Workshop on Evaluation of Liquefaction Resistance of Soils, Salt Lake City, Utah, January 1996. Edited by T.L. Youd and I.M. Idriss. National Center for Earthquake Engineering Research, Report NCEER-97-0022, pp. 41-87.

Robertson, P.K., Woeller, D.J., and Finn, W.D.L. 1992. Seismic cone penetration test for evaluating liquefaction potential under cyclic loading. Canadian Geotechnical Journal, 29: 686-695.

Robertson, P.K., Wride (Fear), C.E., List B.R., Atukorala, U., Biggar, K.W., Byrne, P.M., Campanella, R.G., Cathro, D.C., Chan, D.H., Czajewski, K., Finn, W.D.L., Gu, W.H., Hammamji, Y., Hofmann, B.A., Howie, J.A., Hughes, J., Imrie, A.S., Konrad, J.-M., Küpper, A., Law, T., Lord, E.R.F., Monahan, P.A., Morgenstern, N.R., Phillips, R., Piché, R., Plewes, H.D., Scott, D., Sego, D.C., Sobkowicz, J., Stewart, R.A., Watts, B.D., Woeller, D.J., Youd, T.L., and Zavodni, Z. 2000. The Canadian Liquefaction Experiment: an overview. Canadian Geotechnical Journal, 37: 499-504.

Roy, D., Campanella, R.G., Byrne, P.M., and Hughes, J. 1998. Undrained monotonic behaviour of sand from self-boring pressuremeter. In Proceedings of the Ist International Conference on Geotechnical Site Characterization. Edited by P.K. Robertson and P.W. Mayne. A.A. Balkema, Rotterdam, The Netherlands, Vol. 2, pp. 1349-1354.

Sasitharan, S., Robertson, P.K., Sego, D.C., and Morgenstern, N.R. 1994. State-boundary surface for very loose sand and its practical implications. Canadian Geotechnical Journal, 31: 321-334.

Seed, H.B. 1979. Soil liquefaction and cyclic mobility evaluation for level ground during earthquakes. Journal of the Geotechnical Engineering Division, ASCE, 105(GT2): 201-255.

Seed, H.B., and de Alba, P. 1986. Use of SPT and CPT tests for evaluating the liquefaction resistance of sands. In Use of in-situ tests in geotechnical engineering. American Society of Civil Engineers, Geotechnical Special Publication 6. pp. 281-302.

Seed, R.B., and Harder, L.F. 1990. SPT-based analysis of cyclic pore pressure generation and undrained residual strength. In Proceedings of the $\mathbf{H}$. Bolton Seed Memorial Symposium, Berkeley, Calif. Edited by J.M. Duncan. Vol. 2, pp. 351-376.

Seed, H.B., Tokimatsu, K., Harder, L.F, and Chung, R. 1985. Influence of SPT procedures in soil liquefaction resistance evaluations. Journal of Geotechnical Engineering, ASCE, 111(12): $1425-1445$.

Shibata, T. 1981. Relations between $\mathrm{N}$-value and liquefaction potential of sand deposits. In Proceedings of the 16th Annual Convention of the Japanese Society of Soil Mechanics and Foundation Engineering, Tokyo. pp. 621-624. (In Japanese.)

Shibata, T., and Teparaska, W. 1988. Evaluation of liquefaction potentials of soils using cone penetration tests. Soils and Foundations, 28(2): 49-60.

Stark, T.D., and Mesri, G.M. 1992. Undrained shear strength of liquefied sands for stability analysis. Journal of Geotechnical Engineering, ASCE, 118(11): 1727-1747.

Stark, T.D., and Olson, S.M. 1995. Liquefaction resistance using CPT and field case histories. Journal of Geotechnical Engineering, ASCE, 121(12): 856-869.

Stokoe, K.H., II, Andrus, R.D., Rix, G.J., Sanchez-Salinero, I., Sheu, J.C., and Mok, Y.J. 1988. Field investigation of gravelly soils which did and did not liquefy during the 1983 Borah Peak, Idaho, earthquake. Geotechnical Engineering Center Report GR 87-1, University of Texas at Austin, Austin, Tex.

Suzuki, Y., Tokimatsu, K., Taye, Y., and Kubota, Y. 1995a. Correlation between CPT data and dynamic properties of in-situ frozen samples. In Proceedings of the 3rd International Conference on Recent Advances in Geotechnical Earthquake Engineering and Soil Dynamics, St. Louis, Mo., Vol. 1. pp. 243-250.

Suzuki, Y., Tokimatsu, K., Koyamada, K., Taya, Y., and Kubota, Y. 1995b. Field correlation of soil liquefaction based on CPT data. In CPT'95, Proceedings of the International Symposium on Cone Penetration Testing, Linkoping, Sweden, Vol. 2, pp. 583-588.

Tatsuoka, F., Iwasaki, T., Touida, K., Yasuda, S., Hirose, M., Imai, T., and Kon-no, M. 1980. Standard penetration tests and soil liquefaction potential evaluation. Soils and Foundations, 20(4): 95111.

Tokimatsu, K., and Yoshimi, Y. 1983. Empirical correlation of soil liquefaction based on SPT N-value and fines content. Soils and Foundations, 23(4): 56-74.

Tokimatsu, K., Kuwayama, S., and Tamura, S. 1991. Liquefaction potential evaluation based on Rayleigh wave investigation and its comparison with field behaviour. In Proceedings of the 2 nd International Conference on Recent Advances in Geotechnical Earthquake Engineering and Soil Dynamics, St. Louis, Mo. Edited by S. Prakash. University of Missouri at Rolla, Rolla, Mo., Vol. 1, pp. 357-364.

Vaid, Y.P., and Sivathayalan, S. 1996. Static and cyclic liquefaction potential of Fraser Delta sand in simple shear and triaxial tests. Canadian Geotechnical Journal, 33: 281-289.

Vaid, Y.P., Sivathayalan, S., Eliadorani, A., and Uthayakumar, M. 1996. Laboratory testing at U.B.C. CANLEX Technical Report, Department of Civil Engineering, University of British Columbia, Vancouver.

Verdugo, R. 1992. Characterization of sandy soil behavior under large deformation. Ph.D. thesis, University of Tokyo, Tokyo.

Wride, C.E., and Robertson, P.K. 1997a. Introductory data review report. CANLEX Technical Report, University of Alberta, Edmonton. 
Wride, C.E., and Robertson, P.K. 1997b. Phase II data review report (Massey and Kidd sites, Fraser River Delta). CANLEX Technical Report, University of Alberta, Edmonton.

Wride, C.E., and Robertson, P.K. 1997c. Phases I and III data review report (Mildred Lake and J-pit sites, Syncrude Canada Ltd.). CANLEX Technical Report, University of Alberta, Edmonton.

Wride, C.E., and Robertson, P.K. 1997d. Phase IV data review report (LL Dam and Highmont Dam sites, Highland Valley Copper Mine). CANLEX Technical Report, University of Alberta, Edmonton.

Wride, C.E., McRoberts, E.C., and Robertson, P.K. 1999. Reconsideration of case histories for estimating undrained shear strength in sandy soils. Canadian Geotechnical Journal, 36: 907-933.

Wride (Fear), C.E., Hofmann, B.A., Sego, D.C., Plewes, H.D., Konrad. J.-M., Biggar, K.W., Robertson, P.K., and Monahan, P.A. 2000a. Ground sampling program at the CANLEX test sites. Canadian Geotechnical Journal, 37: 530-542.

Wride (Fear), C.E., Robertson, P.K., Biggar, K.W., Campanella, R.G., Hofmann, B.A., Hughes, J.M.O., Küpper, A., and Woeller,
D.J. 2000b. Interpretation of in situ test results from the CANLEX sites. Canadian Geotechnical Journal, 37: 505-529.

Yoshimi, Y., Tokimatsu, K., and Ohara, J. 1994. In situ liquefaction resistance of clean sands over a wide density range. Géotechnique, 44(3): 479-494.

Yoshimine, M. 1996. Undrained flow deformation of saturated sand under monotonic loading conditions. Ph.D. thesis, University of Tokyo, Tokyo.

Yoshimine, M., Robertson, P.K., and Wride, C.E. 1999. Undrained shear strength of clean sands to trigger flow liquefaction. Canadian Geotechnical Journal, 36(5): 891-906

Youd, T.L., and Idriss, I.M. (Editors). 1997. Proceedings of the National Center for Earthquake Engineering Research (NCEER) Workshop on Evaluation of Liquefaction Resistance of Soils, Salt Lake City, Utah, January 1996. National Center for Earthquake Engineering Research, Report NCEER-97-0022.

Yu, H.S., Schnaid, F., and Collins, I.F. 1996. Analysis of cone pressuremeter tests in sands. Journal of Geotechnical Engineering, ASCE, 122(8): 623-632. 